NASA/TM-2003-212329

\title{
Steady and Unsteady Flow Field Measurements Within a NASA 22-Inch Fan Model
}

Gary G. Podboy, Martin J. Krupar, Stephen M. Helland, and Christopher E. Hughes Glenn Research Center, Cleveland, Ohio 
Since its founding, NASA has been dedicated to the advancement of aeronautics and space science. The NASA Scientific and Technical Information (STI) Program Office plays a key part in helping NASA maintain this important role.

The NASA STI Program Office is operated by Langley Research Center, the Lead Center for NASA's scientific and technical information. The NASA STI Program Office provides access to the NASA STI Database, the largest collection of aeronautical and space science STI in the world. The Program Office is also NASA's institutional mechanism for disseminating the results of its research and development activities. These results are published by NASA in the NASA STI Report Series, which includes the following report types:

- $\quad$ TECHNICAL PUBLICATION. Reports of completed research or a major significant phase of research that present the results of NASA programs and include extensive data or theoretical analysis. Includes compilations of significant scientific and technical data and information deemed to be of continuing reference value. NASA's counterpart of peerreviewed formal professional papers but has less stringent limitations on manuscript length and extent of graphic presentations.

- TECHNICAL MEMORANDUM. Scientific and technical findings that are preliminary or of specialized interest, e.g., quick release reports, working papers, and bibliographies that contain minimal annotation. Does not contain extensive analysis.

- CONTRACTOR REPORT. Scientific and technical findings by NASA-sponsored contractors and grantees.
- CONFERENCE PUBLICATION. Collected papers from scientific and technical conferences, symposia, seminars, or other meetings sponsored or cosponsored by NASA.

- SPECIAL PUBLICATION. Scientific, technical, or historical information from NASA programs, projects, and missions, often concerned with subjects having substantial public interest.

- TECHNICAL TRANSLATION. Englishlanguage translations of foreign scientific and technical material pertinent to NASA's mission.

Specialized services that complement the STI Program Office's diverse offerings include creating custom thesauri, building customized databases, organizing and publishing research results ... even providing videos.

For more information about the NASA STI Program Office, see the following:

- Access the NASA STI Program Home Page at http://www.sti.nasa.gov

- E-mail your question via the Internet to help@sti.nasa.gov

- Fax your question to the NASA Access Help Desk at 301-621-0134

- Telephone the NASA Access Help Desk at 301-621-0390

- Write to:

NASA Access Help Desk

NASA Center for AeroSpace Information 7121 Standard Drive

Hanover, MD 21076 
NASA/TM-2003-212329

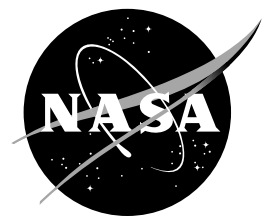

\section{Steady and Unsteady Flow Field Measurements Within a NASA 22-Inch Fan Model}

Gary G. Podboy, Martin J. Krupar, Stephen M. Helland, and Christopher E. Hughes Glenn Research Center, Cleveland, Ohio

Prepared for the

40th Aerospace Sciences Meeting and Exhibit

sponsored by the American Institute of Aeronautics and Astronautics

Reno, Nevada, January 14-17, 2002

National Aeronautics and

Space Administration

Glenn Research Center 


\section{Acknowledgments}

The fan model tested during this experiment was designed and manufactured by General Electric. Hardware was designed and manufactured by General Electric under two NASA contracts, NAS3-26617, Task 63, and NAS3-98004, Task 7.

Trade names or manufacturers' names are used in this report for identification only. This usage does not constitute an official endorsement, either expressed or implied, by the National Aeronautics and Space Administration.

Available from

NASA Center for Aerospace Information 7121 Standard Drive

Hanover, MD 21076
National Technical Information Service 5285 Port Royal Road Springfield, VA 22100 


\title{
STEADY AND UNSTEADY FLOW FIELD MEASUREMENTS WITHIN A NASA 22-INCH FAN MODEL
}

\author{
Gary G. Podboy, ${ }^{*}$ Martin J. Krupar, ${ }^{+}$Stephen M. Helland, ${ }^{+}$and Christopher E. Hughes ${ }^{*}$ \\ National Aeronautics and Space Administration \\ Glenn Research Center \\ Cleveland, Ohio 44135
}

\begin{abstract}
$\underline{\text { Abstract }}$
Results are presented of an experiment conducted to investigate possible sources of fan noise in the flow developed by a 22-in. $(55.9 \mathrm{~cm})$ diameter turbofan model. Flow diagnostic data were acquired to identify possible sources of both tone and broadband noise. Laser Doppler velocimetry was used to characterize the tip flows that develop within the rotor blade passages, the wake flow downstream of the rotor, and the shock waves that develop on the blades when operated at transonic relative tip speeds. Single-point hot-wire measurements were made in the rotor wake to determine the frequency content and the length scales of the flow unsteadiness. The results document the changes in the rotor wake flow with both rotor speed and axial distance downstream of the rotor. The data also show the tip flow development within the blade passage, its migration downstream, and (at high rotor speeds) its merging with the blade wake of the following blade. Data also depict the variation of the tip flow with tip clearance. LDV data obtained within the blade passages at high rotor speeds illustrate the passage-to-passage variation of the mean shock position. Spectra computed from the single-point hot-wire measurements illustrate how the energy in the flow oscillations is split between periodic and random components, and how this split varies with both radial and axial position in the rotor wake.
\end{abstract}

\section{Introduction}

From 1994 through 2001, the Advanced Subsonic Technology (AST) Noise Reduction Program was conducted by NASA in partnership with the FAA, and U.S. aerospace companies for the purpose of reducing aircraft noise. This program involved two parallel efforts; one aimed at reducing airframe noise, the other focused on reducing engine noise. The goal of the engine noise studies was to reduce engine source noise by 6 EPNdB (Effective Perceived Noise dB) by the year 2000 relative to 1992 technology.

A number of experimental tests were conducted during the AST program to quantify the effectiveness of engine noise reduction concepts. The concepts tested included low-noise fan designs, swept and/or leaned stators, active noise control, fan flow management (trailing edge blowing), and scarfed inlets. A review of this work is provided in ref. 1. Of the different sections of a high-bypass ratio engine, (the core, the turbine, the fan, and the jet) the fan is responsible for creating a major portion of the noise developed by the engine when operating near airports at takeoff and approach conditions. Therefore, many of the concepts studied under the AST program have focused on reducing fan noise.

One of the last experimental tests of the AST program was carried out, in part, to identify and characterize noise sources within the fan stage of a turbofan model. This test, conducted at the NASA Glenn 9 X 15 Foot Wind Tunnel in 1999-2000 using a 22-inch $(55.9 \mathrm{~cm})$ diameter turbofan model, is known as the Source Diagnostic Test (SDT). The overall test had many phases, including aerodynamic and acoustic performance testing of two different fans and three different stator designs, acoustic mode measurements using sensors located on the inner surface of the duct, spinning mode measurements using a rotating rake in both the inlet and the nozzle, unsteady surface pressure measurements on a set of stator vanes, and detailed flow field diagnostic measurements using laser Doppler and hot-wire anemometry.

\footnotetext{
* Research Engineer, Member AIAA

${ }^{+}$Research Engineer
}

The detailed flow field measurements made during the Source Diagnostic Test were obtained in order to get a better understanding of the relationship between the flow within the fan stage and the fan noise produced by the test model. Nonuniformities in the flow field within the fan duct can produce noise when they interact with the solid surfaces within the model. These flow field nonuniformities can be sources of either tone or broadband noise. Periodic nonuniformities in the mean flow created by the spinning rotor blades generate noise at discrete frequencies (tone noise), while the random fluctuations in the flow (turbulence) produce broadband noise. For high-bypass ratio engines, both the tone and broadband noise can be significant contributors to the overall level of fan noise. Consequently, to understand how the fan noise is produced, it is important to get a better understanding of both the periodic and random flow field nonuniformities.

There are a number of possible sources of noise in the fan flow. The viscous blade wakes and tip vortices shed from the rotor blades can be important contributors to the noise produced by the fan stage. These wakes and vortices can contain both strong perturbations of the mean flow and high levels of turbulence. The noise produced when these disturbances convect downstream and interact with the stator vanes is known as rotor/stator interaction noise. When operating at high rotational speeds, shocks can form on the rotor blades. These shocks can represent strong, periodic perturbations in the flow. The noise generated by the shocks is known as multiple pure tone or buzzsaw noise. Since broadband noise is generated by the turbulence in the flow, any "source" of turbulence is also a possible source of broadband noise. The turbulence in the rotor flow field is highest in the boundary layers along the hub, case, and blade surfaces and in the viscous wakes and tip vortices shed from the rotor. 
There have been a number of previous experimental investigations aimed at characterizing the flow field nonuniformities which produce fan noise. Martens, et. al. (ref. 2) made measurements both upstream and downstream of the stators inside a 22-inch $(55.9 \mathrm{~cm})$ diameter fan model using hot-wire anemometry in an effort to correlate flow characteristics with noise measurements. Ganz (ref. 3) also used hot-wire anemometry to obtain inlet boundary layer and wake flow data inside an 18 -inch $(45.7 \mathrm{~cm})$ diameter turbofan model. Podboy (ref. 4) compared the wake flow generated by a fan designed by the Allison Engine Co. with a fan designed by Pratt \& Whitney. These studies reveal that the flow field features which are responsible for the generation of fan noise change significantly with RPM, tip clearance, and fan loading. They also suggest that there can be appreciable differences in the fan wake flows generated by different rotors operating at similar conditions. They imply, therefore, that in order to understand how a particular fan generates noise, it is necessary to either measure the flow experimentally, or to use Computational Fluid Dynamics to identify the flow field features responsible for the noise.

The purpose of this paper is to present some of the detailed flow field data obtained during the Source Diagnostic Test. Data were obtained to characterize both the mean and turbulent flow in the vicinity of the rotor. Measurements of the boundary layer along the outer duct wall upstream of the rotor were obtained using subminiature cross-wire probes. LDV data were obtained to characterize the flow in the tip region and in the wake of the rotor. Both single-point (obtained using a single probe) and two-point (obtained simultaneously at two points in the flow using two probes) hot-wire data were obtained downstream of the rotor to learn more about the turbulence in the wake flow. This paper will present some of the LDV and single-point hot-wire wake data obtained during the Source Diagnostic Test.

\section{Experimental Apparatus and Procedure}

\section{Test Model}

Figure 1 shows the $22-$ inch $(55.9 \mathrm{~cm})$ diameter turbofan model installed in the test section of the NASA Glenn 9 X 15 Foot Wind Tunnel. The flow field measurement portion of the Source Diagnostic Test was conducted using two different inlets installed upstream of the fan. The flight inlet, shown in Figure 1, was installed during the inlet boundary layer testing, while a bellmouth inlet was installed during the hot-wire wake and LDV surveys. The flow field measurement studies were conducted with 22 rotor blades, designated as the R4 design by the manufacturer (General Electric), and 26 outlet guide vanes $(\mathrm{OGVs})$ installed within the model. The OGVs were swept back 30 degrees. Table 1 shows some of the design parameters of the R4 blades. The LDV and hot-wire wake measurements were obtained with the tunnel flow set at approximately $0.05 \mathrm{M}$.

Table 1. R4 Rotor Design Parameters

No. of blades

Fan diameter

Corrected tip speed

Corrected RPM (RPMC)

Corrected fan weight flow

Stage pressure ratio

Bypass ratio

Fan radius ratio
22

22 in. $(55.9 \mathrm{~cm})$

$1,215 . \mathrm{ft} / \mathrm{s}(370.3 \mathrm{~m} / \mathrm{s})$

12,656 .

$100.5 \mathrm{lbm} / \mathrm{s}(45.59 \mathrm{~kg} / \mathrm{s})$

1.47

8.85

0.30

\section{Laser Velocimeter System and Data Acquisition}

Figure 2 shows the LDV survey locations relative to the model hardware. In the figure, the surveys are designated as being either shock location, tip flow, or wake surveys. The wake surveys were made at two axial locations between the rotor and stator blade rows, corresponding to 3.12 and 6.49 inches $(7.93$ and $16.48 \mathrm{~cm})$ downstream of the static position of the tip trailing edge. These upstream and downstream wake survey locations will be referred to as axial stations LDV1 and LDV2, respectively. The LDV wake surveys were done at rotor speeds of 6329, 7808, 11074, and 12656 RPMC (50, 61.7, 87.5 and $100 \%$ of the design speed). These data were obtained to determine how the fan wake flow varies with rotor speed and axial position. The constant-radius shock location surveys were conducted at two fan speeds, 11074 and 12656 RPMC. The purpose of these surveys was to define the blade shock structure at these two speeds. The tip flow surveys were conducted at 5 axial locations (corresponding to $25,50,75,100$ and $125 \%$ of the static rotor blade tip chord) and at three different speeds: 7808, 11074, and 12656 RPMC. These surveys were conducted to determine how the tip flow develops within the blade passage and to identify how this development varies with rotor speed.

In order to conduct these LDV surveys it was necessary to place part of the LDV system inside the test section of the wind tunnel. Figure 3 shows a photograph of the LDV traverse system located on the side of the turbofan model. In this photo the bellmouth inlet is shown installed on the model. The traverse was used to move the LDV probe volume radially and axially relative to the model. The LDV system optics are located behind the cylindrical shield shown in the photo. This shield was installed to keep the tunnel flow from striking the optics.

Figure 4 shows a photograph taken with the cylindrical shield removed. In this photo the fiber optic cables used to deliver the laser beams into the tunnel, the transmitting optics used to direct the beams into the model, and one set of receiving optics can be seen. The LDV system is a four-beam, two-color, backscatter system which allows the measurement of two components of velocity simultaneously. Two green beams were used to measure the axial components of velocity, while two blue beams allowed the measurement of tangential components. The photo provided in Figure 4 shows one of two optical arrangements used during the test. Initially, another optical arrangement, one employing two sets of receiving optics (one above and one below the transmitting optics) was used to conduct the wake surveys. During these surveys it was possible to measure both the axial and tangential velocity components simultaneously. Later in the test, however, when the intrablade surveys were attempted, it was found that the reflection of the laser beams off of the rotor blades were drowning out the LDV signals, making it impossible to acquire data using the optical arrangement employed during the wake surveys. To get data within the blade passages it was necessary to position the receiving optics so that they could not "see" the reflection of the beams off of the blades. Since the laser beams were reflecting off the bottom surface of the blades (the pressure surface), it was necessary to position the receiving optics so that they could not see the bottom surface. This requirement meant that the receiving optics had to be positioned at a relatively large angle above the transmitting optics. This arrangement is shown in the photograph of Figure 4. The size of the optical breadboard allowed only one set of receiving optics to be positioned in this way, therefore only one component of velocity could be acquired at a time. Both components of velocity were measured during the intrablade surveys, but they were measured at different times. 
Two windows installed in the side of the model permitted optical access to the internal flow. These two windows are shown in the photograph of Figure 5. The upstream window shown at the right was used during the shock location and tip flow surveys, while the downstream window shown at the left was used to acquire the wake surveys. These windows, made of 0.1 in. thick sodium alumino silicate, were slumped in a furnace (process given in ref. 5) to have the same shape as the inner contour of the model.

The tunnel flow was seeded with polystyrene latex (PSL) spheres that were manufactured at the NASA Glenn Research Center. Figure 6 shows a photograph taken using a scanning electron microscope of a sample of the PSL particles. The white line in the figure corresponds to a length of one micron. Based on this photo, the nominal size of the PSL spheres is estimated to be approximately 0.7 micron in diameter. Due to the manufacturing process, the solid PSL particles are supplied suspended in water. Before introduction into the tunnel this solution is diluted by mixing it with 190 proof ethanol. This diluted solution is then sprayed into the tunnel using a set of nine spray nozzles located approximately 80 feet upstream of the test section. The liquid evaporates in the time it takes to reach the test section, leaving behind the solid PSL seed on which the LDV data was obtained.

The individual velocity measurements are sorted into circumferential bins around the rotor using shaft angle encoders fed with the once-per-revolution signal of the rotor. These encoders segmented the 360 degrees of rotor revolution occurring between two consecutive once-per-revolution pulses into 1100 bins (50 bins per blade passage). Each time a velocity measurement was made, the encoder output was sampled to determine the number of bins generated since the occurrence of the previous once-per-rev pulse. The velocity and corresponding bin number were then stored in the computer as a data pair.

Data were acquired at each measurement location over many rotor revolutions until either a preset number of measurements had been acquired on one of the two LDV channels, or until the maximum time allotted for the data acquisition had elapsed. On-line data plots were used to determine the number of measurements required to accurately resolve the flows occurring within the individual blade passages. In general, the higher the unsteadiness in the flow, the greater the number of measurements required to resolve the flow. On average, more than 40,000 velocity measurements per component were obtained at each combination of measurement location and operating condition.

\section{LDV Data Reduction}

Figure 7 illustrates the data reduction process for a velocity component measured at a given location within the model. The top plot (part A) shows raw, unaveraged velocities sorted into the 1100 bins of a rotor revolution. The first step in the data reduction process is to simply find the average of the velocities occurring within each of the 1100 bins. The resulting mean velocity profile across the entire rotor rev is shown in part B of Figure 7. The next step is to compute the standard deviation (rms) with respect to the mean of the velocities occurring within each bin. This standard deviation, which is a measure of the unsteadiness of the velocity component, will be referred to as the turbulent velocity. Figure 7C shows the resulting turbulent velocity distribution. As can be seen from these plots of the mean and turbulent velocity, there is a high degree of similarity between the flows in the individual blade passages. Consequently, little information would be lost in averaging the data of the 22 blade passages into one average passage. The process of computing average passage distributions form the data is illustrated in Figure 7D for the mean velocities, and in 7E for the turbulent velocities. This step involves folding the mean and turbulent (rms) velocity data of the 22 individual blade passages into one passage and computing the mean within each bin. Velocity distributions which span the 50 bins of a single passage result from this process. A final step in the data reduction is to compute a circumferentially-averaged mean and turbulent velocity from the average passage distributions. The circumferentially-averaged mean velocity is found by determining the mean of the 50 average passage mean velocities, while the circumferentially-averaged turbulent velocity is the mean of the 50 average passage turbulent velocities.

\section{Hot-wire Anemometer System, Data Acquisition and Data Reduction}

Hot-wire wake data were obtained to complement the LDV data and to provide additional information about the turbulence in the wake flow. Specifically, there were two main reasons for acquiring single-point hot-wire data in the rotor wake:

1) The hot-wire probes used during the wake surveys were capable of measuring all three velocity components. Consequently, these probes allowed the measurement of the velocity component not measured during the LDV surveys, the radial component.

2) The output of the hot-wire is a continuous signal which allows the determination of the frequency content and the time scales of the turbulence. Accurate estimates of these quantities could not be obtained from the LDV data.

Figure 8 shows the two axial planes in the rotor wake where hot-wire data were obtained. The two axial locations are 2.96 and 5.89 inches $(7.52$ and $15.0 \mathrm{~cm})$ downstream of the static position of the rotor tip trailing edge. These axial stations will be referred to as HW1 and HW2, respectively. These are displaced slightly from the locations of the LDV surveys, which were 3.12 and 6.49 inches $(7.93$ and $16.5 \mathrm{~cm}$ ) downstream of the rotor tip trailing edge. Blemishes in the downstream LDV window prevented the acquisition of LDV data at the same axial locations as the hot-wire surveys. Hot-wire data were acquired at each axial location with the rotor set at both 6329 and 7808 RPMC. The hot-wire testing was limited to these relatively low rotor speeds since pre-test calibration of the hot-wire probes indicated that there was a good chance that the 5-micron diameter tungsten wires would not survive at higher flow speeds (above $600 \mathrm{ft} / \mathrm{sec}$ ).

Figure 9 shows a photograph of two probes purchased to support the hot-wire testing. These probes differ in the length of the extension used to position the hot-wires upstream of the probe shaft. The short extension is 0.75 inch $(1.91 \mathrm{~cm})$, while the long extension is 1.25 inches $(3.18 \mathrm{~cm})$. Probes having a 1.25 inch extension were used to obtain the single-point wake data provided herein. These 4-wire probes were custom-made by Auspex Corp. and are believed to be the smallest commercially-available 3-component hot-wire probes. The four wires make a dual cross-wire arrangement, with one set of cross-wires aligned with, and one set of cross-wires perpendicular to, the probe shaft. The perpendicular distance between a set of prongs holding a wire is on the order of $1 \mathrm{~mm}$.

The probes were calibrated in a temperature-controlled, 3.5 inch $(8.89 \mathrm{~cm})$ diameter freejet. The calibration process consists of the following steps:

1) With the jet flow temperature set at $115 \mathrm{deg} F(46.1 \mathrm{C})$,

a) the probe is aligned with the flow (pitch=yaw $=0$ degrees) and the output of each of the 4 wires is recorded as the jet flow is varied from 100 to $600 \mathrm{ft} / \mathrm{sec}(30.5$ to $183 \mathrm{~m} / \mathrm{s})$ in 
increments of $50 \mathrm{ft} / \mathrm{sec}(15.2 \mathrm{~m} / \mathrm{s})$.

b) at two speeds, $300 \mathrm{ft} / \mathrm{sec}$ and $500 \mathrm{ft} / \mathrm{sec}(91.4$ and 152 $\mathrm{m} / \mathrm{s}$ ), the probe is calibrated vs. flow angle. At each of these speeds, the probe is calibrated over a 49 point pitch/yaw matrix which varies from -30 to +30 degrees in increments of 10 degrees.

2) The probe is then calibrated at three other temperatures: 85 , 100 , and $130 \mathrm{deg} F(29.4,37.8$, and 54.4 C). The calibration done at these other temperatures is the same as that listed above in step 1a.

From this calibration it is possible to determine how the output of the probe varies with speed, flow angle, and temperature. By measuring the flow temperature within the model using thermocouples, it is possible to correct for changes in temperature between the calibration jet flow and the experiment. The relation used to make this correction is:

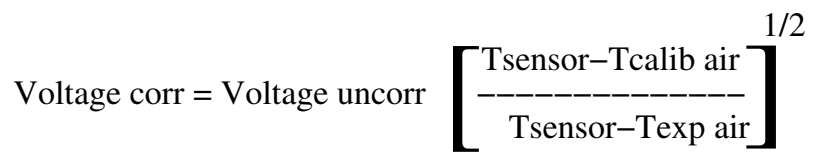

The thermocouple data used to make this correction can only be used to get an estimate of the average temperature occurring at a given axial and radial location in the wake flow. Therefore, no attempt is made to correct for circumferential temperature variations in the flow such as those resulting from the passing of the blade wakes.

In practice, the above temperature correction can correspond to a large correction to the hot-wire velocities. For the data obtained in this test, the speeds were corrected by roughly $25 \%$. Obviously, this is a very significant correction. To apply an accurate correction to the data, it is necessary to determine the experimental flow temperature accurately. However, the thermocouple rake data were not acquired at the same locations as the hot-wire data. To obtain estimates of the flow temperature at the hot-wire measurement locations, the output of a CFD code, APNASA, was used to determine the change in temperature between the thermocouple rake and hot-wire measurement locations. The hot-wire velocity corrections are, therefore, not only dependent on the accuracy of the thermocouple measurements, but on the CFD as well. Because of the rather complicated process used to obtain flow speed from the hot-wire data, it is believed that the mean velocities resulting from the LDV measurements are more accurate. Consequently, most of the the mean velocities presented below in the Results section were obtained using LDV. The hot-wire measurements were used primarily to learn more about oscillations of the flow about the mean, ie. about the flow unsteadiness.

In addition to the temperature correction, an attempt is also made to correct the hot-wire data for differences in flow density between the calibration and experiment. However, since the flow density is not measured, this correction is based on differences in static pressure between the two flows. This correction is made using the following relation:

$$
\text { Vel corr }=\text { Vel uncorr }\left[\begin{array}{c}
\text { Pstat cal } \\
------- \\
\text { Pstat exp }
\end{array}\right]
$$

The experimental static pressure is derived from rake total pressure/total temperature and LDV velocity measurements made in the wake flow.

Acquisition of a complete survey of single-point hot-wire wake data involved the following steps:

1) Mounting the probe at the desired axial location.

2) Yawing the probe to 40 degrees so that it would be roughly

NASA/TM-2003-212329 in line with the swirling wake flow.

3) Traversing the probe radially to a desired measurement location.

4) Recording the output of the 4 wires and the once-per-rev signal from the model at a sampling rate of $200 \mathrm{kHz}$ for one second.

Steps 3 and 4 were then repeated until data were acquired at some 50 different radial locations across the span of the wake flow. Sampling for one second ensured that data were acquired over more than 100 rotor revolutions.

With the sampling rate fixed, the number of measurements obtained per rev can vary due to slight variations of rotor speed. This poses a problem since in order to average the data of the different revs together it is necessary for each rev to have the same number of measurements. In the post-processing, each rev of data was interpolated to provide the same number of measurements per rev. The data obtained at 6329 RPMC (50\% of design) were interpolated to 1760 measurements per rev ( 80 measurements across each blade passage), while the data obtained at 7808 RPMC $(61.7 \%$ speed), were interpolated to 1430 measurements per rev (65 measurements per blade passage).

After interpolating, the data were then reduced in a manner similar to that used with the LDV data. First, distributions of the mean and rms (turbulent) velocity across the rev were computed. Then the data of the 22 individual blade passages were folded and averaged to provide average passage distributions of mean and turbulent velocity. Finally, circumferentially-averaged mean and turbulent velocities were determined by finding the mean of the average passage distributions.

\section{$\underline{\text { Results }}$}

\section{Wake Surveys}

LDV and hot-wire data were obtained in the wake of the $\mathrm{R} 4$ rotor in order to obtain a better understanding of the flow field nonuniformities which contribute to the rotor/stator interaction noise produced by the test model. The viscous blade wakes and tip vortices are the main contributors to this rotor/stator interaction noise. Periodic variations in the mean flow generate discrete tones, while random fluctuations in the flow contribute to the broadband noise. The noise is produced when the wake flow nonuniformities convect downstream and interact with the stator vanes.

\section{$\underline{\text { LDV }} \underline{\text { Measured Mean Flow }}$}

Figure 10 shows LDV measured mean velocities that were acquired at axial station LDV1 with the rotor operating at $100 \%$ speed (12656 RPMC). Contours of mean axial velocity are plotted at the top, contours of tangential velocity at the bottom. The view depicted in these figures is from behind the rotor, looking upstream, at a slice in the flow field occurring at axial station LDV1, downstream of the rotor. These plots show average passage results, with the average passage data duplicated to provide a better view of any transitions which may occur across the boundaries of the passage. In this downstream-looking-upstream view, the rotor blades rotate clockwise. These plots clearly identify two distinct regions in the flow field: 1) a viscous region made up of the blade wakes and tip flows, and 2) a potential flow region comprising the "clean" part of the passage flow outside the viscous regions. Within the potential flow region axial velocities are remarkably uniform, while tangential velocities are uniform over the outer part of the passage and then increase gradually with decreased radius. In contrast to the potential flow region, the viscous blade wakes and tip flows represent strong perturbations in the mean flow. In general, at a given radius, 
axial velocities are lower and tangential velocities higher in the viscous part of the flow.

Figure 11 shows the data of Figure 10 replotted to illustrate more clearly the magnitude of the nonuniformities in the mean flow. The contours plotted here show the average passage mean velocities after subtracting, at each radial location, the circumferentially-averaged mean velocity. Thus, these plots illustrate how the average-passage mean flow deviates from the circumferential average. These contour plots can be used to locate the regions in the rotor wake where the largest perturbations in the mean flow occur. For this $100 \%$ speed condition, the plots show that the largest perturbations of the axial component occur within the viscous blade wakes, while the largest tangential component perturbations occur in the tip flow. Of these two components, the perturbations in the tangential velocities are thought to be more important in the generation of rotor/stator interaction noise. This noise is created due to unsteady loading on the vanes which, in turn, is caused primarily by the oscillation of the velocity component normal to the vane surface. Of the two, the tangential component is more aligned with the vane surface normal direction and, therefore, more likely to generate rotor/stator interaction noise.

Figure 12 shows contours of this same parameter (the difference between the average passage mean velocities and the circumferentially-averaged mean velocity measured at each radius) computed from the tangential velocities measured at axial station LDV1 for all four or the tested rotor speeds. Figure 13 also shows this parameter, but these plots correspond to data obtained further downstream at axial station LDV2. In general, at a given radial location, the greater the change in the tangential mean velocity across the blade passage, the higher the unsteady loading on the downstream stator vanes. The unsteady loading caused by the oscillations of the mean flow has an effect on the level of rotor/stator interaction tone noise produced.

Figure 14 was generated to illustrate how the amplitude of the tangential mean velocity oscillations measured in the rotor wake vary with measurement location and rotor speed. The values plotted were determined by finding the difference between the maximum and minimum average passage tangential mean velocities measured at each measurement location/rotor speed combination. Two sets of line plots are presented, with each set showing radial distributions corresponding to the four tested speeds. Part a) of the figure shows the distributions calculated from data measured at axial station LDV1, while part b) shows the results of data measured at station LDV2. From these plots, the following observations can be made:

1) The station LDV1 and LDV2 plots are similar in that each set show the amplitude of the tangential mean velocity oscillations increasing gradually with rotor speed in the hub region.

2) Both sets also show that further out in the flow (for $7 "<\mathrm{r}<10 "(17.8-25.4 \mathrm{~cm}$, or $34-84 \%$ span) at station LDV1 and $8 "<\mathrm{r}<10 "(20.3-25.4 \mathrm{~cm}$, or $45-80 \%$ span $)$ at station LDV2) the amplitude of the tangential mean velocity oscillations increase as rotor speed is increased from $50 \%$ to $87.5 \%$, but then decrease slightly as speed is increased further to $100 \%$. The "choppy" nature of the $87.5 \%$ and $100 \%$ speed curves between $r=8$ " and $r=10 "$ (roughly $50-80 \%$ span) is believed to be caused by shocks on the R4 blades at these speeds.

3 ) In the tip flow region ( $r>10 "$, or $r>25 \mathrm{~cm}$, or $r>85 \%$ span) the amplitudes of the tangential mean velocity oscillations increase with rotor speed all the way up to $100 \%$ speed at station LDV1. However, at station LDV2 the amplitudes increase only up to $87.5 \%$ speed, then drop off as speed is increased further to $100 \%$.

4) The largest tangential mean velocity perturbations are generated by the outer part of the blade.

5) A comparison of the LDV1 and LDV2 station curves illustrates that the amplitude of the mean flow oscillations decrease rapidly with distance downstream of the rotor. In fact, except for at the tip, the amplitudes measured at $100 \%$ speed at axial station LDV2 are actually lower than those measured at $50 \%$ speed at station LDV1.

\section{$\underline{\text { LDV Measured Unsteady Flow }}$}

While rotor/stator interaction tone noise can be related to the amplitude (and phase) of the mean flow variations in the rotor wake flow, rotor/stator interaction broadband noise is a function of the turbulence level in the wake flow. Figure 15 shows contours of axial and tangential turbulent velocity measured at axial station LDV1 with the rotor operating at $100 \%$ speed. These show the demarcation between the viscous and potential flow regions even more clearly than the mean velocity plots of Figure 10. The viscous regions in the flow are very unsteady, while the potential flow regions between the wakes and inboard of the tip flow are relatively constant. The unsteadiness is greatest in the blade wakes between radii of 7 and 9.5 inches $(18-24 \mathrm{~cm}$, or 35-75\% span hub-to-tip) and in the tip region near where the blade wake meets the outer case. For each component the peak level of turbulent velocity found in the tip region is slightly higher than that found in the blade wake. The contours also show that the peak level of turbulent velocity measured for the two components is roughly the same, near $70 \mathrm{ft} / \mathrm{sec}(21 \mathrm{~m} / \mathrm{s})$. As was the case with tone noise, of the two measured, the tangential component fluctuations are expected to be more important contributors to the generation of broadband noise.

The contour plots of Figure 16 illustrate the change with rotor speed in the tangential turbulent velocities measured at axial station LDV1. The contours show that the viscous (turbulent) regions in the flow tend to become thinner as the the rotor speed is increased. At the two lowest speeds, 50 and $61.7 \%$ of the design speed, a relatively thick region of unsteady flow extends completely across the passage along the outer case. At $87.5 \%$ speed the tip flow is more localized, extending only about halfway across the passage. At $100 \%$ speed the tip flow is even more concentrated and shows up in the plot as a relatively small region of highly turbulent flow off to the side of the blade wake. At this high speed condition, the peak tangential turbulent velocities in the tip region are higher than in the blade wake, while at the three lower speeds the peak levels in the two regions are about the same.

The plots of Figure 17 show the tangential turbulent velocities measured further downstream, at axial station LDV2. A comparison of these contours with those of Figure 16 reveals that the viscous regions in the flow widen and the turbulent velocity levels decrease as the flow moves downstream. The widest wakes occur at the lowest measured speed, with those measured at 50\% speed and station LDV2 occupying over half of the circumferential extent of the passage at the outer radial locations. These downstream data show the unsteadiness in the tip region to be higher than in the blade wake at all four rotor speeds. Since this was not the case at axial station LDV1, it appears that the wakes and tip flows dissipate at different rates as they convect downstream, with the tip flow unsteadiness more persistent. This may be due to the continuous "supply" of turbulence in the tip region created by the fan case boundary layer and/or to the radial migration of the blade wake unsteadiness into the tip region. Since the tip region unsteadiness decays more slowly, the relative acoustic importance of the two sources shifts to the tip region as the flow moves downstream of the rotor. If the 
stators were positioned close to the rotor, at or upstream of axial station LDV1, both the blade wakes and tip flows could be expected to contribute significantly to the rotor/stator interaction broadband noise, especially at rotor speeds at and below $87.5 \%$. With the stators located downstream, as they were tested here, the tip flows would be expected to be the main contributors to the broadband noise.

The line plots of Figure 18 illustrate how the maximum tangential turbulent velocity measured during the different wake flow surveys varies with rotor speed and axial location. The values measured at the two axial locations, LDV1 and LDV2, show the same trend - the max measured tangential turbulent velocity increases almost linearly with rotor speed. The main deviation from the linear trend occurs at $61.7 \%$ speed, with these values slightly higher than the almost exact linear relationship suggested by the data of the other 3 speeds. The dissipation of the max measured value with downstream distance is rather consistent across the 4 speeds, with the downstream values ranging between 24 to $31 \%$ lower than the upstream values. The turbulence measured at the outer radial locations at axial station LDV2 can be expected to dissipate further before interacting with the swept stator vanes to produce rotor/stator broadband interaction noise.

\section{Shock surveys}

Data were acquired along the constant-radius survey locations denoted by the green line of Figure 2 in an effort to determine the character of the shocks which exist on the blades when operating at high rotor speeds. Figure 19 shows contours of average passage relative Mach number computed from the measured axial and tangential velocities. The left plot shows relative Mach number contours computed from measurements made at $87.5 \%$ speed (11074 RPMC), while the right plot shows contours for $100 \%$ speed (12656 RPMC). The upstream portion of the R4 blade cross-section at this radius $\left(\mathrm{r}=10.36^{\prime \prime}\right.$ or $26.3 \mathrm{~cm}$ ) is superimposed on the contours. The rotor blades would rotate downward in this view and the axial flow would be right-to-left. These contours clearly identify the normal shock which exists on the suction side of the rotor blades. This shock moves downstream along the suction side of the blade and increases in strength as rotor speed is increased from 87.5 to $100 \%$ speed. At $100 \%$ speed the shock has moved downstream to a location only about $10 \%$ of the rotor blade chord upstream of the leading edge of the adjacent blade. Thus, the data are showing that even at $100 \%$ speed the shock does not move downstream far enough to be "swallowed" into the blade passage. With the shocks free to propagate upstream of the rotor it is likely that the strong perturbations of the mean flow created by the shocks are a significant source of tone noise emanating from the inlet.

Another view of the shock structure measured at $100 \%$ speed is depicted in Figure 20. The left plot provided in the figure is a repeat of the $100 \%$ speed average passage relative Mach number contours presented in Figure 19. The right plot also shows average passage relative Mach number contours measured at $100 \%$ speed, but here they are shown as computed from measurements made in the tip region during a constant-axial survey made at approximately $25 \%$ chord. The approximate axial location of the constant-axial survey (data shown in the right plot) is indicated by the dashed line in the left contour plot, while the radial location of the constant-radius survey (data shown in the left plot) is indicated by the dashed line in the right contour plot. The view depicted in the right plot is aft-looking-forward, so the rotor blades would rotate clockwise. The two black triangles overlayed on the contours represent regions where data could not be acquired because the blades blocked the field of view of the LDV receiving optics. The contours illustrate the extent of the supersonic and subsonic regions of the flow at this axial location and rotor speed. They also show the expected decrease in the shock strength with decreasing radius.

The blade-to-blade differences in the strength and position of the shocks are thought to be responsible for the generation of multiple pure tone noise (ref. 6). The plots of Figure 21 illustrate the variation of the mean shock position across the blade passages. The contour lines plotted in the figures show an overlay of the Mach $=1$ contours measured in the 22 individual blade passages. Only contour lines corresponding to the deceleration of the flow through the shock are presented. The Mach $=1$ contours resulting from the acceleration of the flow to supersonic relative speeds in the expansion region between the shocks were omitted for clarity. These plots indicate that the variation of the shock position from passage-to-passage is roughly the same at the two speeds, spanning a distance equal to roughly $8 \%$ of the blade chord.

\section{Tip Flow Surveys}

Data were acquired from constant-axial surveys in the tip region of the rotor to obtain information on how the tip flow develops within the blade passage. Previous investigations conducted at NASA Glenn indicate that the fan tip flow can migrate across the blade passage as it moves downstream (ref. 7 and 8). Figure 22 shows contours of tangential turbulent velocity measured near the outer case during the present study at seven axial locations within the model (the 5 tip flow and 2 wake survey locations). Contours are provided for two different rotor speeds; $61.7 \%$ speed data are plotted on the left and $87.5 \%$ speed data are plotted on the right. The contours for each speed are presented from top to bottom in the order of increasing downstream distance within the model. The data measured at the two different speeds show the same trend regarding the dissipation of the peak levels of turbulent velocity with downstream distance. That is, the peak levels are highest at the upstream-most axial station (25\% chord); they then decrease while the tip flow thickens and moves downstream. Just downstream of the rotor, at $125 \%$ chord, the peak levels are roughly $2 / 3$ rds of the peak levels measured at $25 \%$ chord.

While the dissipation of the turbulence with axial distance in the tip region is similar at these two speeds, there are differences in the circumferential location of the tip flow within the passage. The tip flow measured at $61.7 \%$ speed is almost centered in the passage at $25 \%$ chord, and stays centered as it moves downstream. In contrast, at $87.5 \%$ speed and $25 \%$ chord, the tip flow is smaller in circumferential extent and is located much closer to the suction side of the blade. At $87.5 \%$ speed, as the tip flow moves downstream it appears to migrate away from the blade, toward the pressure side of the adjacent blade. By the time the flow reaches the downstream-most axial location, LDV2, the tip flow appears to have merged with the unsteadiness in the blade wake of the following blade.

Figure 23 shows the corresponding tangential turbulent velocities measured at the highest tested rotor speed, $100 \%$. In this figure, the contours corresponding to the seven different axial locations within the model are presented twice; those presented at the left were all plotted using the same colorbar (that provided to the left of the contours), while the contour plots presented at the right were plotted using different colorbars (not shown), each having a range corresponding to the minimum and maximum turbulent velocities measured within each of the seven axial planes. Consequently, the left contours can be used to determine how the turbulent velocity levels vary with downstream distance, 
while the contours at the right provide a better view of the circumferential migration of the tip flow as it convects downstream. The line of turbulent flow extending radially inward from the outer case in the $25 \%$ chord contours is due to the normal shock located on the upstream portion of the blade shown previously in Figure 20. This shock also shows up in the $50 \%$ chord contours as the region of unsteadiness just off the suction side of the blade. At this high speed condition, the tip flow extends only a short distance radially into the passage. The outermost part of the tip flow right next to the outer wall could not be measured due to increased optical noise levels associated with flare light off the window and blade tips. The data do, however, provide an indication of the location of the tip flow circumferentially within the blade passage. At $25 \%$ chord the tip flow is just off the suction side of the blade, between the blade and the shock. At $50 \%$ chord the tip flow is on the opposite side of the shock, roughly one-third of the blade gap off the suction side of the blade. As the flow moves downstream, the tip flow lags further and further behind the blade from which it was generated and, consequently, continues to migrate across the passage toward the pressure side of the following blade. At axial station LDV1 the tip flow appears to have migrated over to the wake of the adjacent blade. This migration of the tip flow to the adjacent blade wake did not occur until further downstream with the rotor at $87.5 \%$ speed. Thus, the data are indicating that the migration of the tip flow occurs more rapidly when the rotor speed is increased.

The tip flow data presented here indicate that the rotor wake plots need to be interpreted carefully. The close proximity of the blade wakes and tip flows in the downstream data plots might lead one to conclude that both emanated from the same blade. The data acquired within the passage indicates that this was not the case. Much of the highly unsteady flow near the fan case just to the pressure side of the blade wake shown in the downstream-most plots actually comes from the adjacent (preceding) blade.

The data also indicate that the entire chordwise extent of the blade tip does not contribute equally to the formation of the tip clearance flow, especially at high rotor speeds. In the 87.5 and $100 \%$ speed contours plotted in Figures 22 and 23, the tip flow has already moved off the blade and into the passage at the $50 \%$ chord location. In addition, the data show a decrease in the maximum turbulent velocity measured in the tip region with increasing downstream distance. This suggests that even at the upstream-most location at which tip flow data were obtained, $25 \%$ chord, the tip flow may already be dissipating. This would imply that the blade tip upstream of the $25 \%$ chord location is responsible for the generation of the tip clearance flow. This should not be too surprising considering that at these high rotor speeds a shock exists on the suction side of the blades (see Figs 19-21). It is likely that the blade loading is much higher upstream of the shock. This high loading would promote the development of the tip clearance flow.

All of the data presented above were obtained with a rubstrip installed within the model which was designed to provide a 0.020 " clearance between the blade tip and the case at the stacking axis of the rotor with the fan operating at $100 \%$ speed. A limited amount of LDV data were also obtained with what was called a "nominal" rubstrip installed in the fan case. This nominal rubstrip was designed so that the fan would actually rub into the rubstrip at $100 \%$ speed, thus providing no clearance between the fan and the duct at this speed. During the testing it was determined that the actual rotor speed at which the fan rubbed into the rubstrip was $100.7 \%$ speed. The clearance at $100 \%$ speed was estimated to be less than 0.005". The LDV surveys made with the nominal rubstrip installed were limited to two tip flow surveys at axial station LDV1, one at 87.5 and another at $100 \%$ speed. The objective of this testing was to determine how the tip flow changes with tip clearance. Figure 24 shows a comparison of average passage tangential turbulent velocities measured with the two rubstrips installed. Plots are presented for both of the tested speeds, with $87.5 \%$ speed data on the left and $100 \%$ speed data on the right. The plots show that the tip clearance change has a big effect on the character of the tip flow measured in the fan wake. The tip flow disturbance generated with the larger tip clearance extends radially approximately $30 \%$ further into the passage. The peak levels of tangential turbulent velocity are also higher with the larger tip gap - about $15 \%$ higher at $87.5 \%$ speed, and $25 \%$ higher at $100 \%$ speed. At each of the two speeds, the tip flow also appears to migrate circumferentially over to the adjacent blade wake more rapidly when the tip gap is larger. This suggests that it is the strength of the tip clearance flow, not just the rotor speed, which dictates how rapidly the tip flow migrates across the blade passage.

\section{Hot-wire Wake Surveys}

There were two main reasons for conducting the hot-wire wake surveys: 1) to measure the velocity component not measured with LDV, the radial component, and 2) to learn more about the flow unsteadiness. The continuous output of the hot-wire anemometers allows the determination of the frequency content and the time scales of the flow unsteadiness. In addition, by invoking Taylor's frozen turbulence assumption, the time scales can be used to obtain estimates of the flow's turbulence length scales.

Length scales available from single-point hot-wire measurements correspond to length scales in the streamwise direction. Consequently, when discussing length scales, rather than working with axial, tangential, and radial components, it is better to use a coordinate system in which one of the 3 coordinate directions is in the streamwise direction, and the other two are perpendicular to it. As defined here, the streamwise direction at a given axial and radial measurement location is parallel to the circumferentially-averaged total velocity vector measured at that point in space. The plane perpendicular to this streamwise direction will be referred to as the cross-stream plane. In this cross-stream plane we define two orthogonal directions: 1) the spanwise direction, out away from the rig centerline, and 2) the upwash direction, perpendicular to the streamwise and spanwise directions such that streamwise, upwash, and spanwise directions make up a right-handed coordinate system. Note that since the streamwise direction is always parallel to the local circumferentially-averaged total velocity vector, the orientation of the coordinate axes will vary with measurement location. Also note that the upwash and spanwise components of velocity are defined such that their circumferentially-averaged values are always zero. These two components are, therefore, small in comparison to the streamwise component. Consequently, this coordinate system allows all three average-passage mean velocity components to be displayed on one plot, with the streamwise velocities shown as color contours and the two cross-stream components resolved into secondary velocity vectors that can be overlayed on top of the color contours.

Figure 25 shows an example of such a plot. Note that the secondary velocity vectors presented in the figure do not actually lie in the plane of the figure. However, for presentation purposes, they are shown as if they did lie in this plane. That is, the vector magnitudes were not altered to account for the oblique angles between the cross-stream planes in which the vectors actually lie and the axial plane in which they are presented. The data presented here were acquired at axial station HW2 with the rotor at $61.7 \%$ speed. 
Plots created from hot-wire data obtained at the three other combinations of axial station and rotor speed are all similar to the plot shown here, in that they all show the viscous blade wakes having higher than average upwash and spanwise velocities. Thus, when viewed in this coordinate system, the flow in the viscous wakes tends to be flung radially outward and in the direction of rotor rotation, while the flow in the clean part of the passage, between the viscous blade wakes, has a tendency to move in the opposite direction.

For a given rotor wake flow, in order to minimize the unsteady lift on the downstream stator vanes (and perhaps, decrease the tone noise), it would be necessary to orient the vanes so that the amplitude of the mean flow oscillations normal to the vane surface is minimized. For the flow depicted in Figure 25, this could be achieved by leaning the vanes so that their leading edges are parallel to the predominant flow direction indicated by the secondary flow velocity vectors in the viscous blade wake. The data indicate that the amount of stator lean required to minimize the unsteady lift would increase gradually from almost no lean near the hub to a maximum near $80 \%$ span, and then decrease back toward no lean at the outer case. The required stator lean would be in the opposite direction to the lean of the viscous blade wake.

The plot displayed in Figure 25 shows that the viscous blade wakes have spread to occupy a little less than half of the circumferential extent of the passage at this downstream axial location. Rather than showing abrupt changes in velocity across the blade wake like those expected just downstream of a blade trailing edge, the secondary velocity vectors show a relatively smooth circumferential variation. The shape of this wave-like variation of the mean flow is expected to have an effect on the frequency content of the tone noise generated by the blade wake/stator vane interaction. If allowed to interact with the stators, thin, deep blade wakes having abrupt changes in velocity at their edges would tend to generate noise at the fundamental blade passing frequency (BPF) and a number of harmonics of BPF. The tone noise resulting from smoothly-varying wakes, like those shown here, would be concentrated in the BPF tone and only one or two harmonics.

Insights as to the character of the noise spectrum resulting from the rotor wake/stator vane interaction can be obtained by examining power spectra computed from the hot-wire time traces. Figure 26 shows a comparison of power spectra computed from the upwash velocities measured at the two locations, HW1 (shown in black) and HW2 (red), with the rotor at $61.7 \%$ speed. Three separate plots are presented in the figure, corresponding to three different spanwise locations in the wake flow: 25,81 , and $97 \%$ span from the hub. At $97 \%$ span the probe was located in the tip flow and, therefore, the flow measured by the probe was always turbulent (ie. there is no clean, potential flow region at the tip). The spectra corresponding to this tip location show high broadband levels, with little tonal content. They also show that the spectrum levels decrease between stations HW1 and HW2 over the entire frequency range. This is due to the dissipation of the turbulence as it convects downstream of the rotor. Further inboard, at 81 and $25 \%$ span, the flow measured by the probe oscillated between high and low turbulence as the viscous blade wakes, separated by the clean passage flow, passed by. Consequently, the spectra for these two inner spanwise locations contain the combined effects of both the turbulent and nonturbulent segments of the upwash velocity time traces. In these spectra the tones corresponding to the blade passing frequency (BPF) and its harmonics stand out above the broadband levels. The broadband levels decrease between 81 and $25 \%$ span, reflecting the fact that the viscous blade wakes occupy a smaller percentage of the blade gap, and the turbulent velocity levels within the wakes decrease, as the hub is approached. Because of the reduced broadband levels, it is possible to identify more harmonics of the BPF tone at $25 \%$ span, but these harmonics contain significantly less energy than those measured at $81 \%$ span. At both inner spanwise locations (81 and 25\% span), the BPF harmonics decrease between stations HW1 and HW2, indicating that the the wakes becomes more sinusoidal in shape as they propagate downstream.

In Figure 27 power spectra of the upwash velocity component are compared to spectra based on the von Karman model of isotropic turbulence. The experimental spectra presented here were computed after subtracting the periodic component (the mean flow oscillation) from the upwash velocity time traces. This removes the tones, leaving only the broadband, or turbulent part of the spectra. To compare with the von Karman spectra, the experimental spectrum levels were adjusted by multiplying by the circumferentially averaged streamwise velocity and dividing by the product of the variance and the integral length scale of the streamwise turbulent velocity. This method of normalizing the spectrum levels was found to provide good agreement between measured and von Karman spectra for data acquired downstream of a fan tested at Boeing by Ganz, et. al. (ref. 9). For the data presented in Figure 27, the following observations can be made: 1) The experimental spectra tend to match the shape of the von Karman spectra better at the downstream axial location. This indicates that the turbulence becomes more isotropic as it moves downstream. 2) The experimental levels are higher than the von Karman levels. This suggests that the method used to normalize the experimental spectra did not collapse the data down to the levels of the von Karman spectra. If the turbulence was isotropic the normalization method would have succeeded in collapsing the data down to these levels. 3) The experimental spectra for data acquired at both axial stations at $97 \%$ span tend to roll off with a slope of $-5 / 3 \mathrm{rds}$, like the von Karman spectra, whereas the other 4 experimental spectra tend to roll off more slowly than the model below about $20 \mathrm{khz}$, and more rapidly than the model above this frequency. Thus, in the tip region the spectra show an inertial subrange, whereas in the blade wake this region is not clearly identified. The rapid roll-off the experimental spectra above $20 \mathrm{kHz}$ is believed to be caused by the limited frequency response of the hot-wire system. 4) The poorest match between experimental and von Karman spectra occurs for the data acquired at the upstream axial station at $25 \%$ span. The experimental spectra for this case show elevated energy levels at frequencies between 10 $\mathrm{kHz}$ and $20 \mathrm{kHz}$. The mismatch between the experimental and von Karman spectra at this location should not be too surprising given that the flow is turbulent for only a fraction of the blade passing period.

Radial distributions of turbulence integral length scale calculated from hot-wire velocity time traces measured at axial stations HW1 and HW2 with the rotor operating at $61.7 \%$ speed are presented in Figure 28. Length scales corresponding to all three velocity components (streamwise, upwash, and spanwise) are plotted in the figure. The length scale estimate for a given velocity component at a given radial location was determined by extrapolating the corresponding power spectrum to zero frequency following the method outlined in ref. 9. Like the turbulence spectra presented in Figure 27, the power spectra from which the length scale estimates were made were computed after subtracting the periodic part of the signal (the mean flow oscillation) from the velocity time traces. From the plot of Figure 28 the following observations can be made: 1) The length scales tend to be longer at the downstream axial location, HW2. This is consistent with the previously discussed result that the unsteady flow regions tend to get thicker as they move 
downstream. 2) The length scales for the streamwise component are longer than those of the two cross-stream components (the upwash and spanwise). For isotropic turbulence the ratio of the streamwise to cross-stream length scales is $2: 1$. The data presented here do show roughly a $2: 1$ ratio between the length scales of the streamwise and upwash components at the downstream axial location for radii between 7 and 10 inches (18 - 25 cm or $25-80 \%$ span). However, most of the other data plotted in Figure 28 would provide streamwise to cross-stream length scale ratios larger than two. 3) The length scales tend to be the longest in the tip region. In particular, the streamwise and upwash length scales increase dramatically as the outer case is approached. 4) At the upstream location inboard of the tip flow, the length scales of the two cross-stream components are about the same magnitude, indicating that the turbulence is axisymmetric. 5) Between stations HW1 and HW2, at the inner radii, the length scales of the upwash component grow more rapidly than those of the spanwise component, indicating that the turbulence gets less axisymmetric. This may be due to an influence of the swept stators on the flow. In the hub region the stators are only a short distance downstream of station HW2.

\section{Conclusions}

1) The R4 rotor wake flow can be thought of as containing two distinct regions: 1) a viscous region made up of the blade wakes and tip flows, and 2) a potential flow region comprising the "clean" part of the passage flow outside the viscous regions. In the potential flow regions, mean velocities are relatively uniform and unsteadiness is low. Within the viscous regions, mean velocities change significantly and unsteadiness is high.

2) Plots were provided which illustrate the nonuniformities in the mean wake flow. The amplitude of the mean flow perturbations decreased significantly as the flow moved downstream of the rotor. The largest tangential mean velocity perturbations were generated by the outer part of the blade. How these nonuniformities change with rotor speed was found to depend on the location in the wake flow. In particular,

a) In the hub region the amplitude of the tangential mean velocity oscillations increased consistently with rotor speed.

b) Further out in the passage, the amplitude of the tangential mean velocity oscillations increased as rotor speed was increased from $50 \%$ to $87.5 \%$, but then decreased slightly as speed was increased further to $100 \%$.

c) In the tip flow region (the outer 1 " of span), the amplitude of the tangential mean velocity oscillations increased with rotor speed all the way up to $100 \%$ speed at station LDV1, but at station LDV2 they increased only up to $87.5 \%$ speed, then dropped off as speed was increased further to $100 \%$.

3) Contour plots were provided which illustrate the unsteadiness in the rotor wake flow. These plots show:

a) The turbulent regions in the flow get thinner as rotor speed is increased.

b) At the three lowest tested speeds and the upstream measurement station (LDV1), the peak levels of tangential turbulent velocity measured in the blade wake and in the tip flow were about the same. At the highest tested rotor speed, the peak level measured in the tip was higher than in the wake.

c) At station LDV2, the peak levels of tangential turbulent velocity measured in the tip were higher than those measured in the blade wake at all four tested speeds.

d) The unsteadiness in the blade wakes decayed more rapidly with downstream distance than the unsteadiness in the tip flow. e) The maximum tangential turbulent velocity measured within a plane downstream of the rotor increased almost linearly with rotor speed.

f) The maximum tangential turbulent velocity measured in the flow dissipated by roughly the same percentage between stations LDV1 and LDV2 regardless of rotor speed.

4) Contour plots of relative Mach number were provided which illustrate the mean location of the shocks emanating from the R4 blades at both 87.5 and $100 \%$ speed. These data show:

a) The shock moves downstream as the rotor speed is increased from 87.5 to $100 \%$ speed.

b) At both 87.5 and $100 \%$ speed, the shock extends upstream of the leading edge of the following blade (ie. the shock is not swallowed).

c) The variation of the mean shock position from passage-to-passage is roughly the same at the two speeds, spanning a distance equal to roughly $8 \%$ of the blade chord.

5) Contour plots were presented which illustrate the propagation of the tip flow both within and downstream of the blade passage. These show that:

a) At $61.7 \%$ speed a relatively thick region of unsteady flow extends across the blade passage in the tip region. The point of maximum unsteadiness within this region stays roughly centered between the two adjacent blades (and blade wakes) as it moves downstream.

b) As the rotor speed is increased the tip flow becomes smaller and more localized.

c) At high speed $(87.5 \%$ and $100 \%)$ the tip flow migrates from the suction surface of the blade from which it was formed toward the adjacent (following) blade. This migration of the tip flow occurs more rapidly as rotor speed is increased. Downstream of the rotor the tip flow merges with the blade wake of the adjacent (following) blade.

d) At high rotor speeds, the upstream portion of the blade tip is responsible for generating the tip flow.

6) Contour plots were presented which illustrate the effect of changes in the rotor blade tip clearance on the unsteady flow downstream of the tip. LDV data were obtained with two different rubstrips installed in the model, one designed to provide a tip clearance of 0.020 " at $100 \%$ speed, and one which provided less than 0.005 " clearance at the same speed.

a) The tip flow disturbance measured downstream of the rotor extended approximately $30 \%$ further into the passage with the larger tip clearance.

b) The peak levels of tangential turbulent velocity measured within the tip flow were higher with the larger tip gap about $15 \%$ higher at $87.5 \%$ speed, and $25 \%$ higher at $100 \%$ speed.

7) A three-component velocity plot showing the rotor wake flow measured using hot-wire anemometry indicates that the unsteady lift on the downstream stator vanes could be minimized by leaning the stator vanes in the opposite direction to the lean of the viscous blade wake. At $61.7 \%$ speed the optimum lean would increase gradually from almost no lean near the hub to a maximum near $80 \%$ span, and then decrease back toward no lean at the outer case.

8) Power spectral density plots made from upwash velocities measured in the rotor wake show the unsteadiness in the tip flow to be broadband, with little tonal content. At radial locations inboard of the tip flow, broadband levels decrease and tones in the spectra are revealed.

9) Comparison of measured upwash velocity power spectral densities with those based on the von Karman model of 
isotropic turbulence indicate better agreement in the tip flow region than in the blade wake region. The agreement is also better at the downstream axial location as compared to the upsteam location.

10) Turbulence integral length scales computed from hot-wire data obtained in the rotor wake indicate:

a) Some of the data show roughly a 2:1 ratio of streamwise to cross-stream length scale ratio (as would be the case if the turbulence were isotropic). However, most of the measured wake data provide ratios greater than 2 .

b) Length scales tend to be the longest in the tip region.

c) At the upstream measurement location (HW1) and radial locations inboard of the tip flow, the turbulence is rather axisymmetric. At the downstream axial location the turbulence was found to be less axisymmetric.

\section{References}

1. Envia, E., "Fan Noise Reduction: An Overview," AIAA Paper 2001-0661, 2001.

2. Martens, S., Shin, H., and Gliebe, P.,"Rotor Wake Unsteady Flowfield Hot-wire Measurements in the Universal Propulsion Simulator (UPS) at NASA," GE Aircraft Engines TM 97-67.

3. Ganz, U.W.,, "Experimental Investigation of the Unsteady Flow Characteristics in the Boeing 18 Inch Fan Rig," AIAA Paper 99-1886, 1999.
4. Podboy, G.G., "Further Analysis of Fan Wake Data Obtained Downstream of the Allison Low Noise Fan and the Pratt \& Whitney ADP Fan 1 Models," AST Engine Noise Workshop, Vol IV, pp. 131-160, April 1998.

5. Verhoff, V.G., "Three-Dimensional Laser Window Formation," NASA/RP 1280, 1992.

6. Hayden, R.E., Bliss, D.B., Murray, B.S., Chandiramani, K.L., Smullin, J.I., Schwaar, P.G., "Analysis and Design of a High Speed, Low Noise Aircraft Fan Incorporating Swept Leading Edge Rotor and Stator Blades," NASA CR-135092, 1977.

7. Suder, K.L., and Celestina, M.L., "Experimental and Computational Investigation of the Tip Clearance Flow in a Transonic Axial Compressor Rotor," ASME Journal of Turbomachinery, Vol. 118, pp. 218-229, 1996.

8. Van Zante, D.E., Strazisar, A.J., Wood, J.R., Hathaway, M.D., Okiishi, T.H., "Recommendations for Achieving Accurate Numerical Simulation of Tip Clearance Flows in Transonic Compressor Rotors," Journal of Turbomachinery, Vol. 122, pp. 733-742, October 2000.

9. Ganz, U.W., Joppa, P.D., Patten, T.J., Scharpf, D.F., "Boeing 18-Inch Fan Rig Broadband Noise Test," NASA CR-1998-208704, 1998 


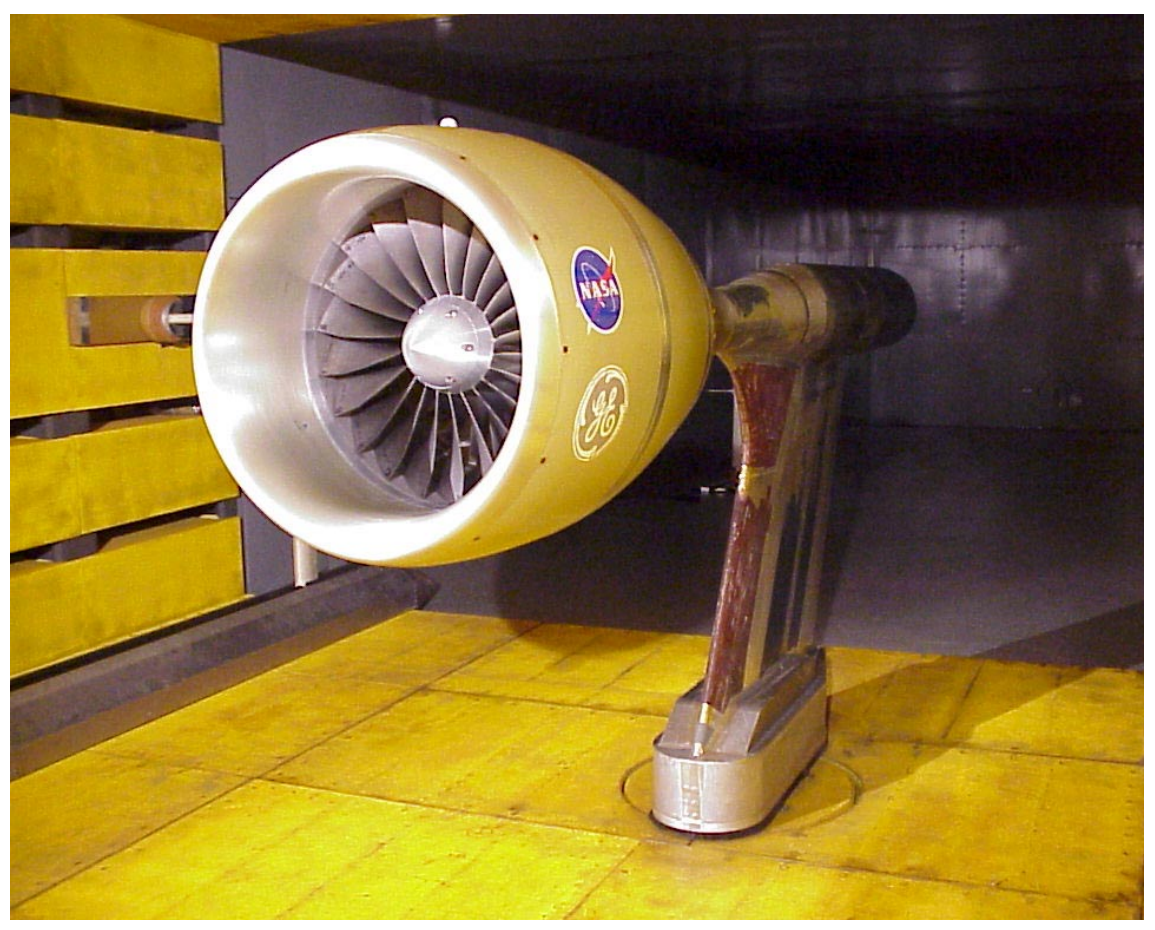

Figure 1. Source Diagnostic Test model installed in the NASA Glenn 9 X 15 Foot Wind Tunnel

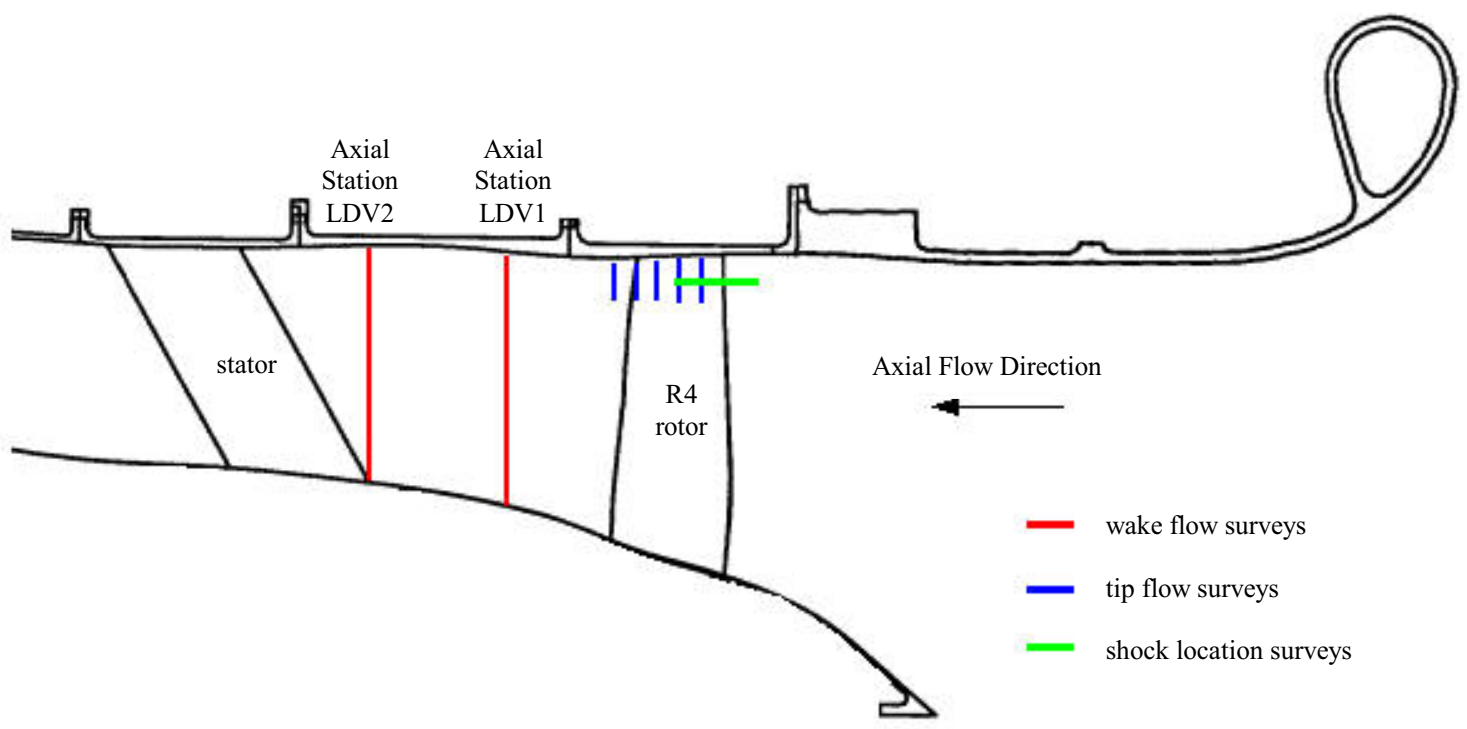

Figure 2. Schematic showing side view of model and location of LDV surveys. 


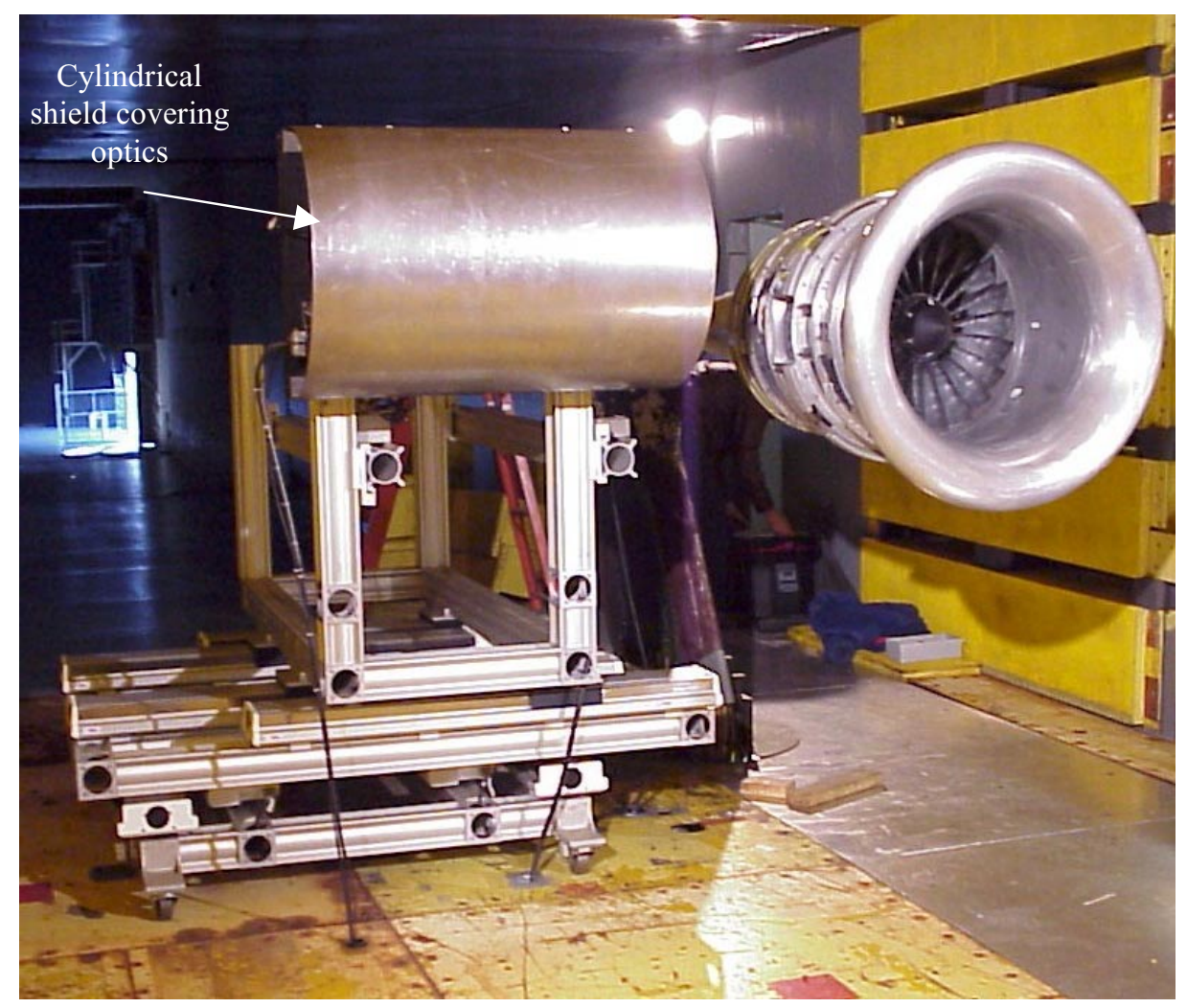

Figure 3. LDV system hardware installed next to the SDT model in the NASA Glenn 9 X 15 Foot Wind Tunnel.

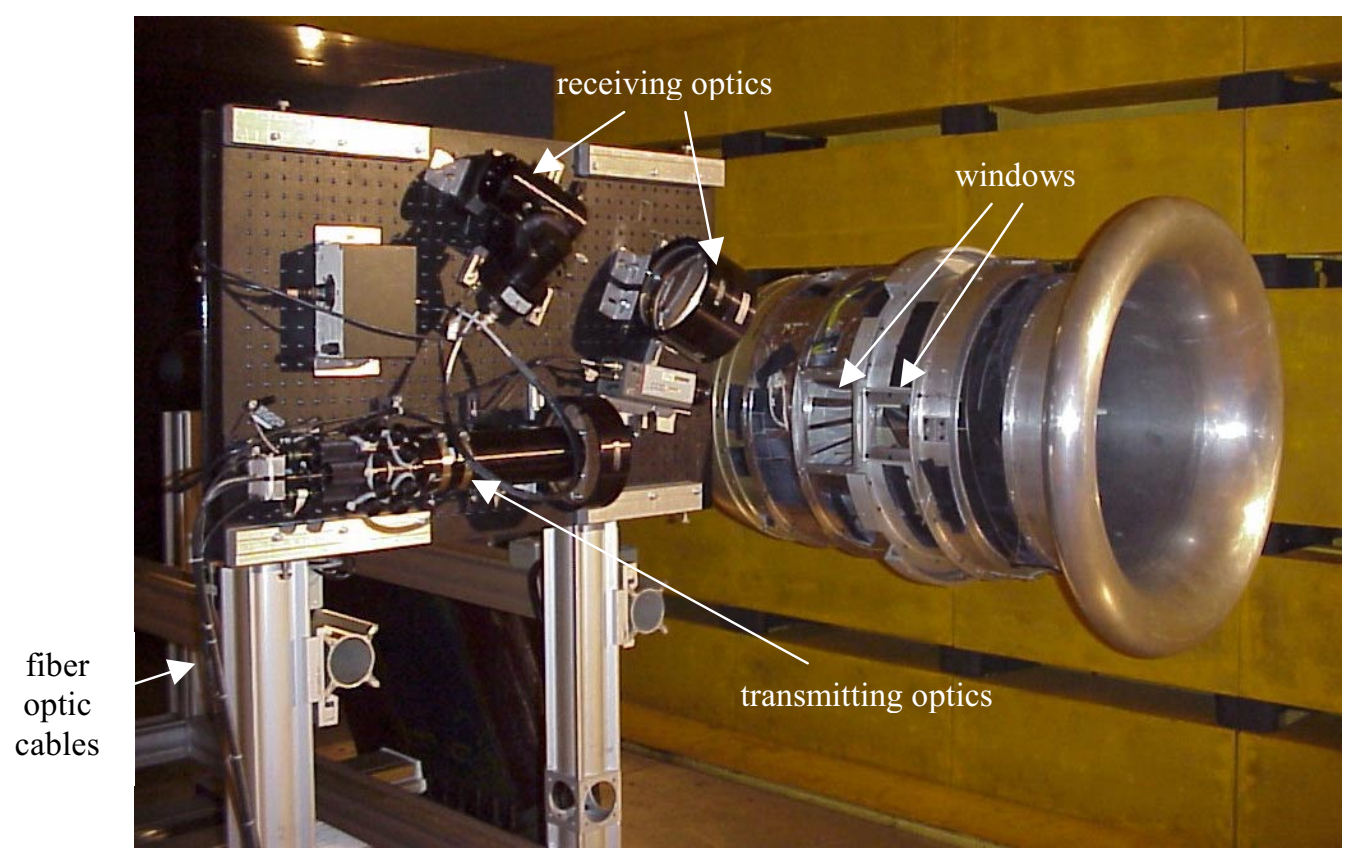

Figure 4. Photo of LDV optics mounted to traverse. 


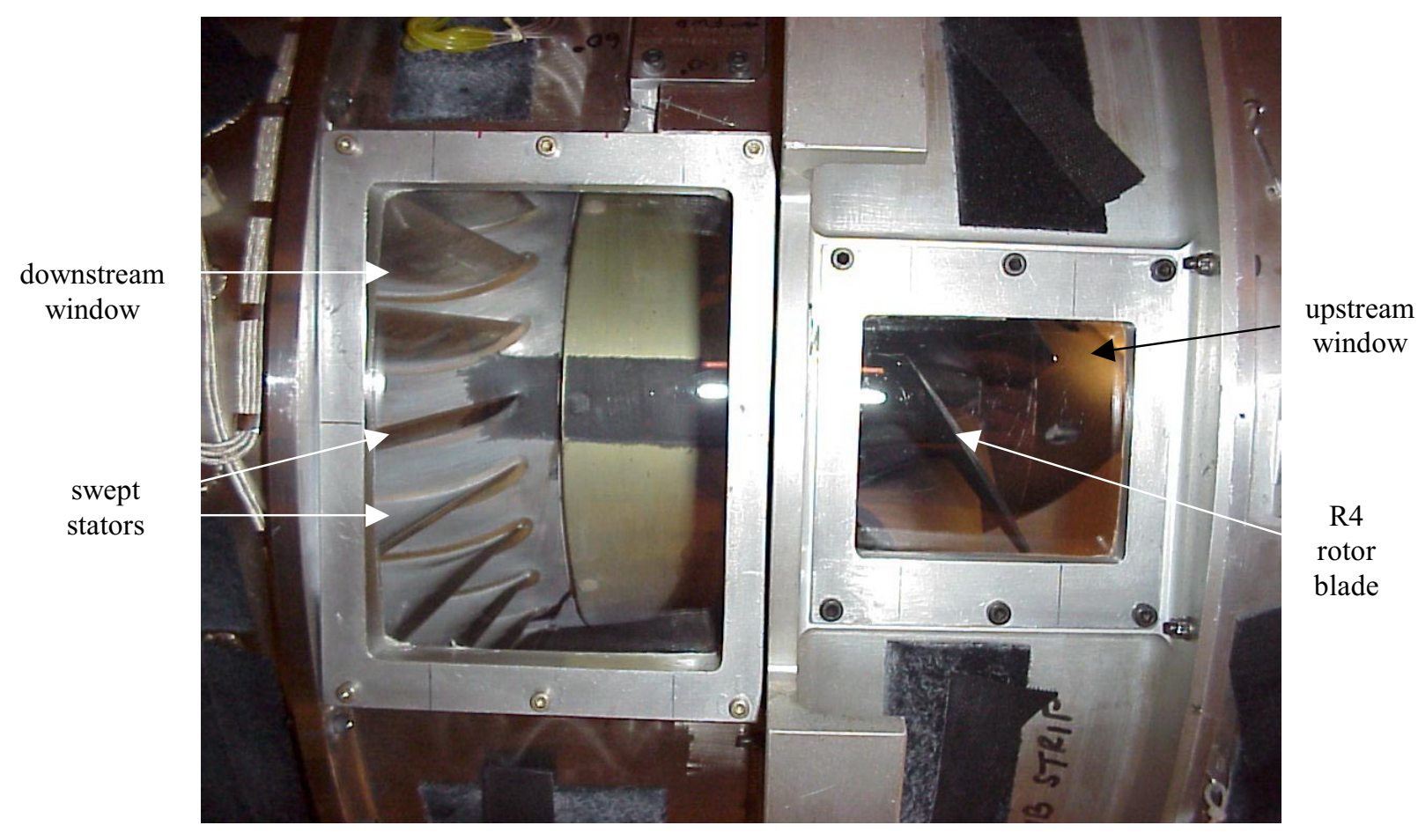

Figure 5. Photo of windows installed in the SDT model.

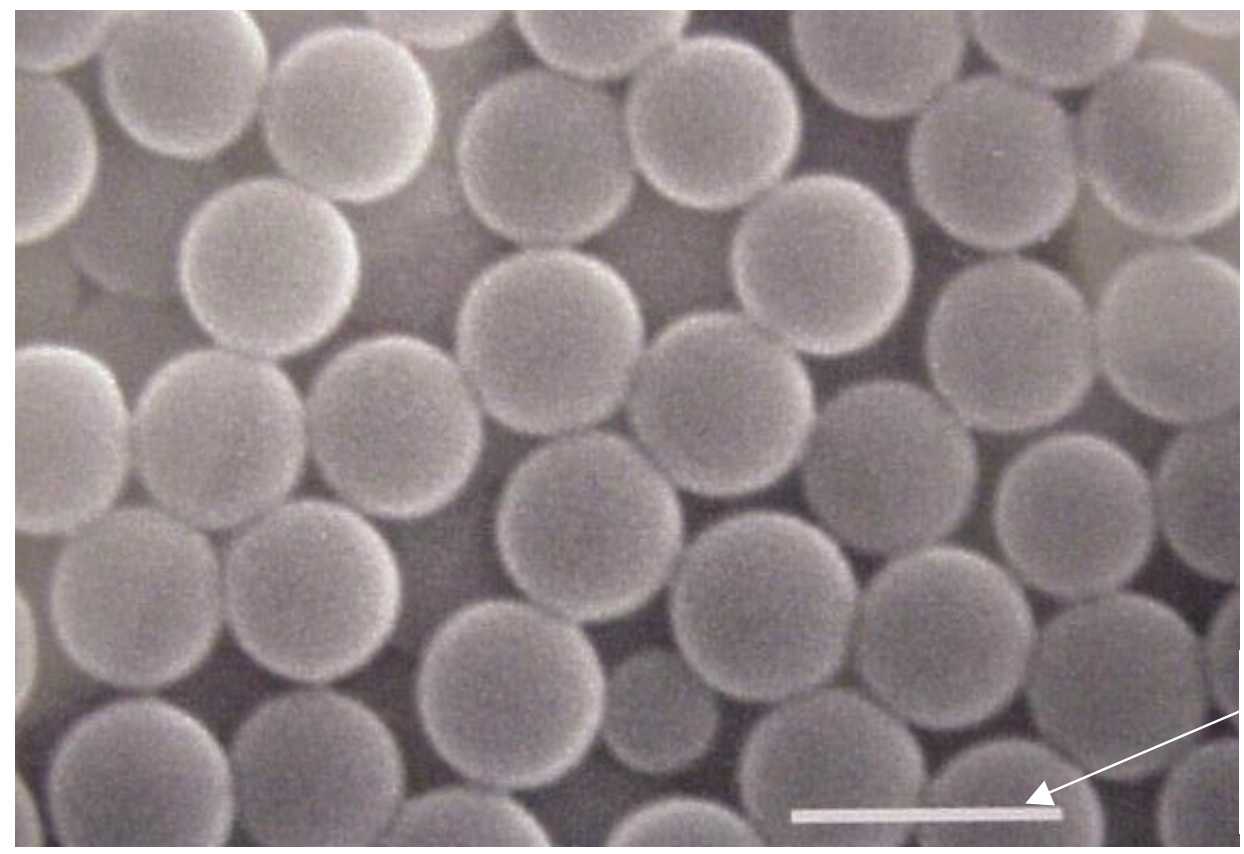

length of white line corresponds to one micron

Figure 6. Scanning electron microscope photo of polystyrene latex particles used as LDV seed. 
A) Raw, unaveraged velocities sorted into 1100 circumferential bins.
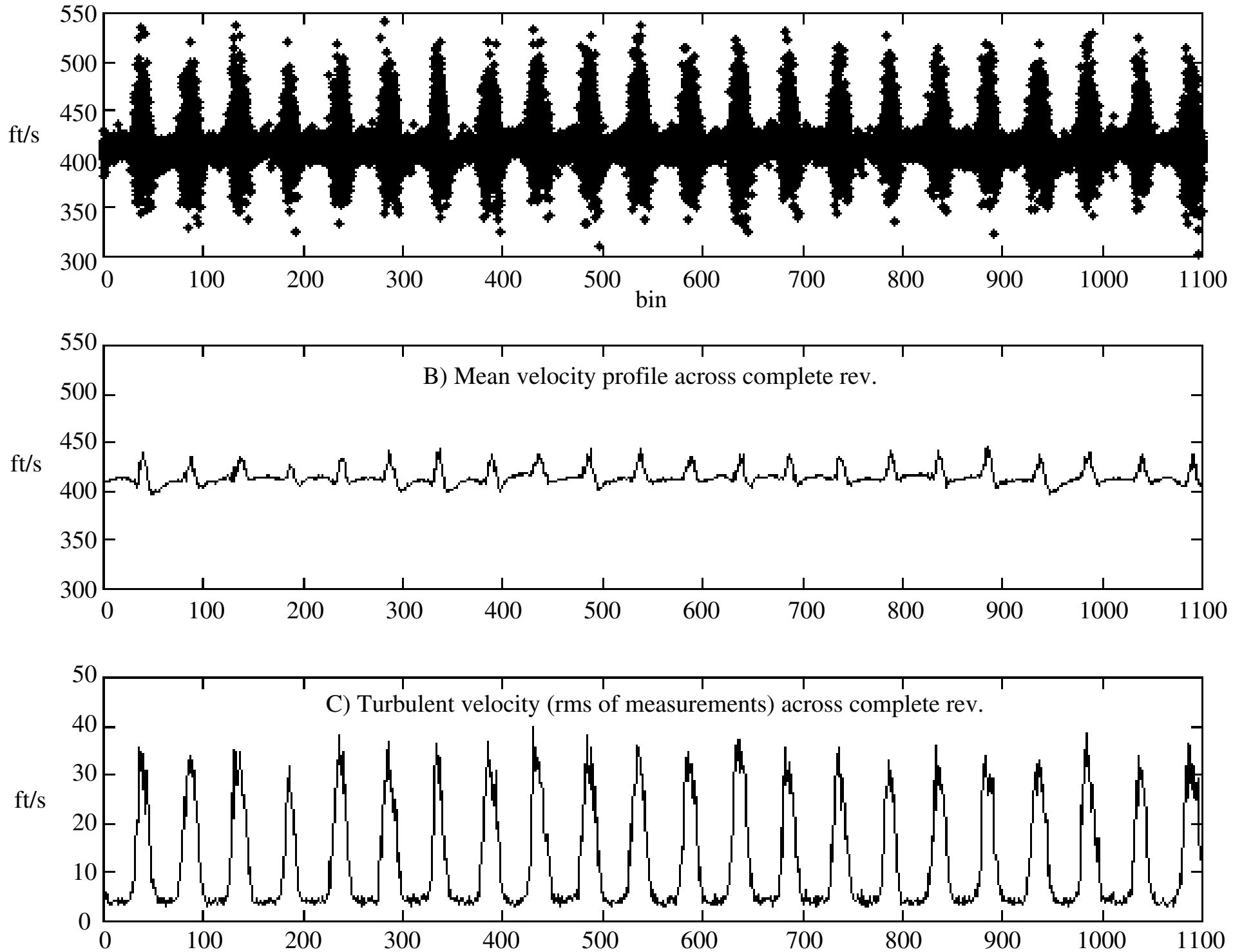

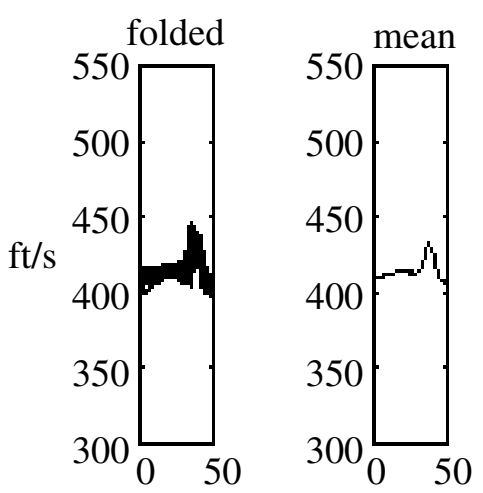

D) "average passage" mean velocities

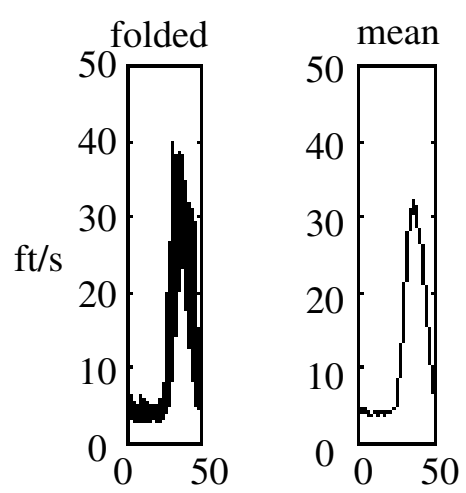

E) "average passage" turbulent velocities

Figure 7. Illustration of LDV data reduction process. 


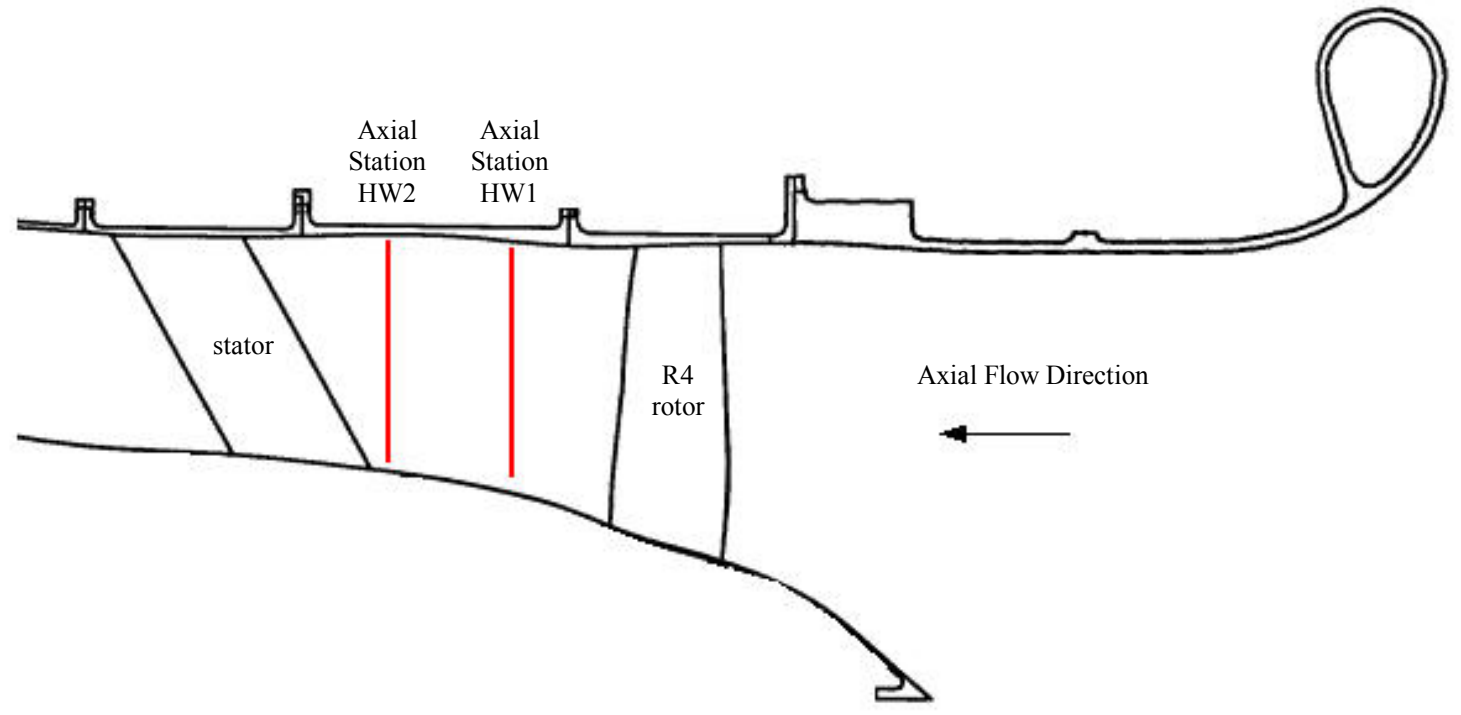

Figure 8. Schematic showing side view of model and location of single-point hot-wire wake surveys.

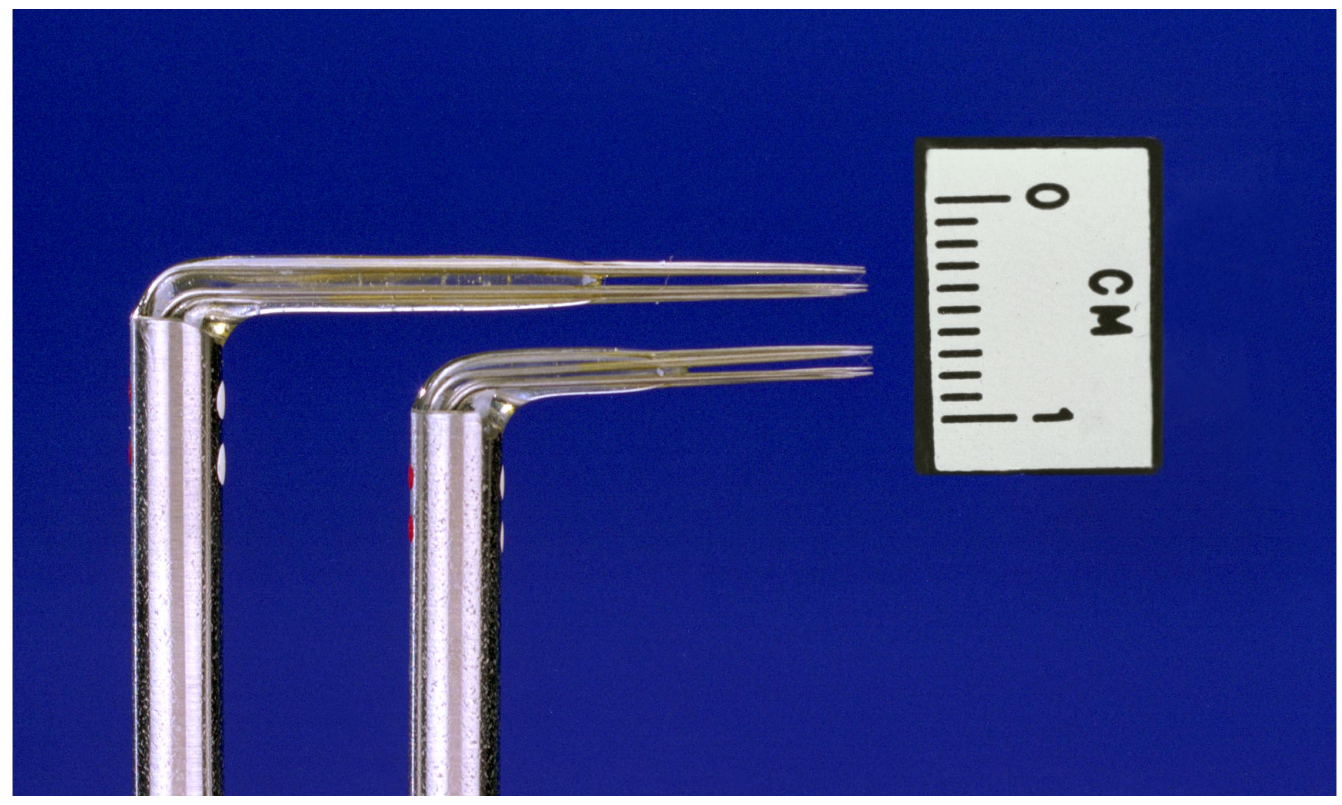

Figure 9. Photo of 4-wire 3-component hot-wire probes. 


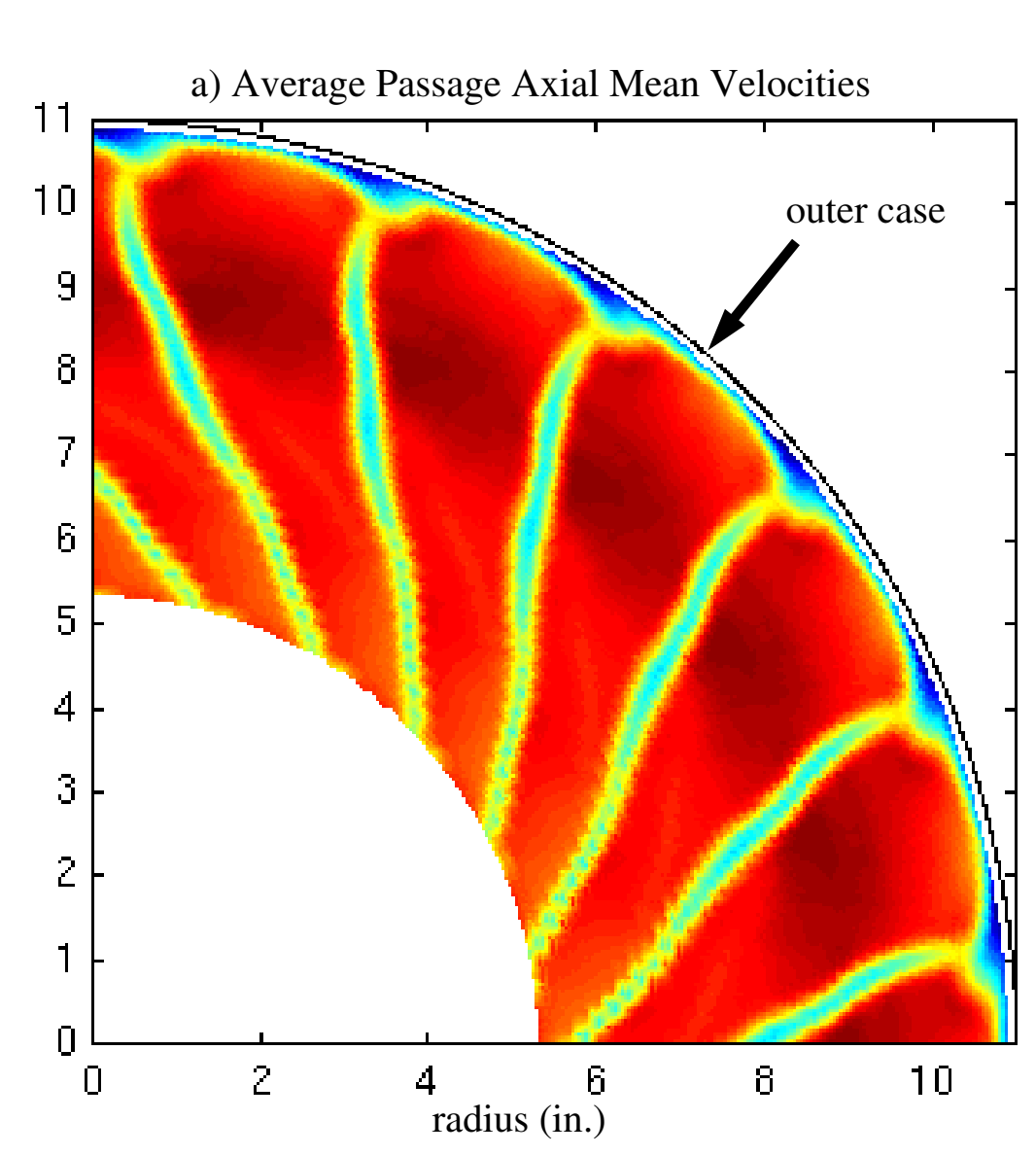

\section{$\mathrm{ft} / \mathrm{sec}$}

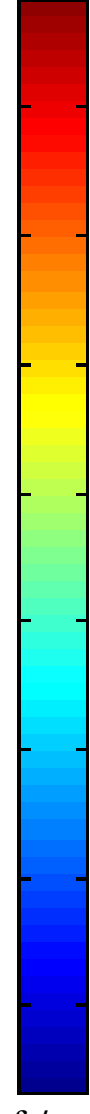

580

560

540

520

580

480

460

440

b) Average Passage Tangential Mean Velocities

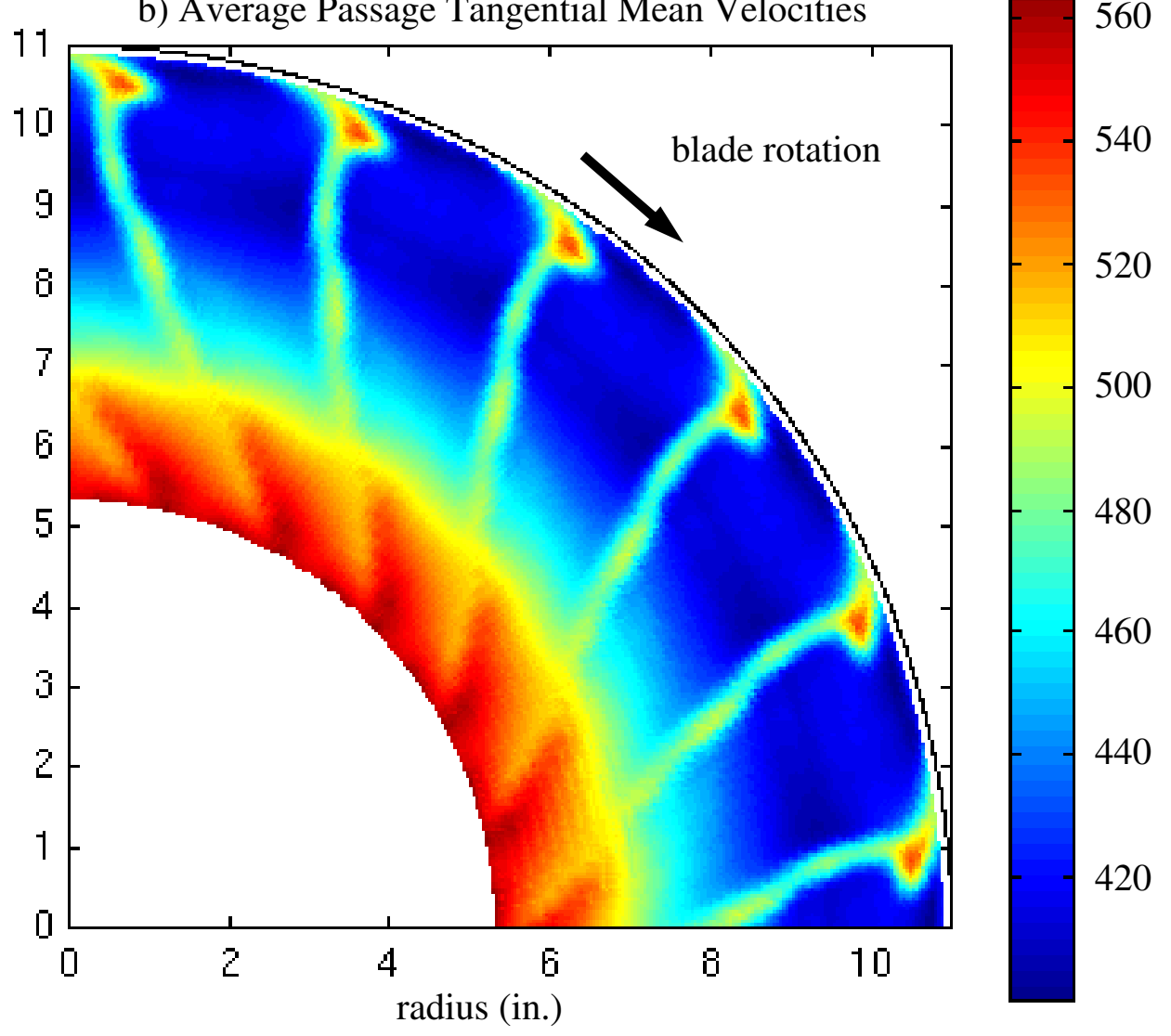

Figure 10. Average passage mean velocities measured at axial station LDV1 at $100 \%$ rotor speed. 


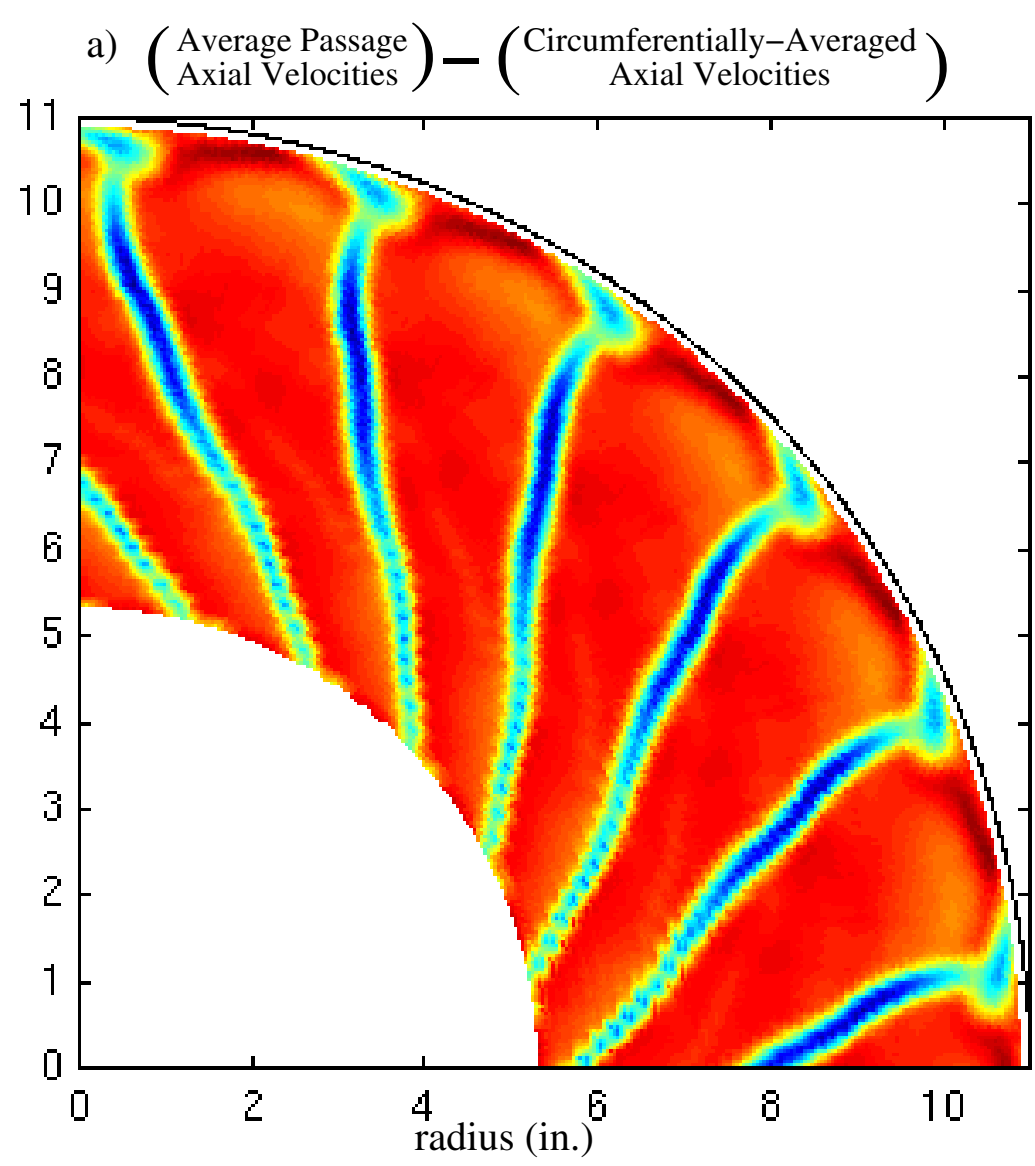

$\mathrm{ft} / \mathrm{sec}$
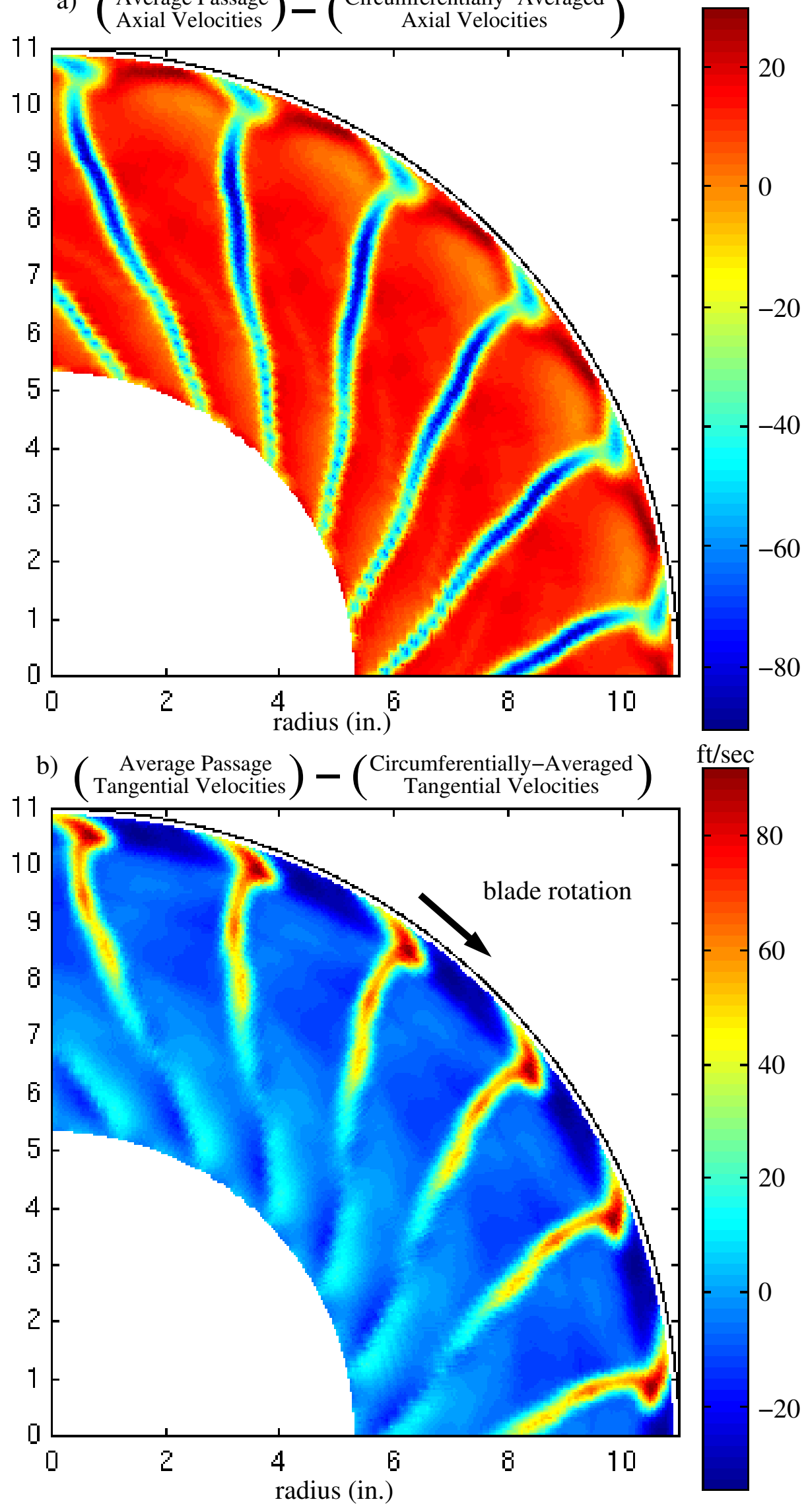

Figure 11. Difference between average passage mean velocities and circumferentially-averaged velocities measured at axial station LDV1 at $100 \%$ rotor speed. 


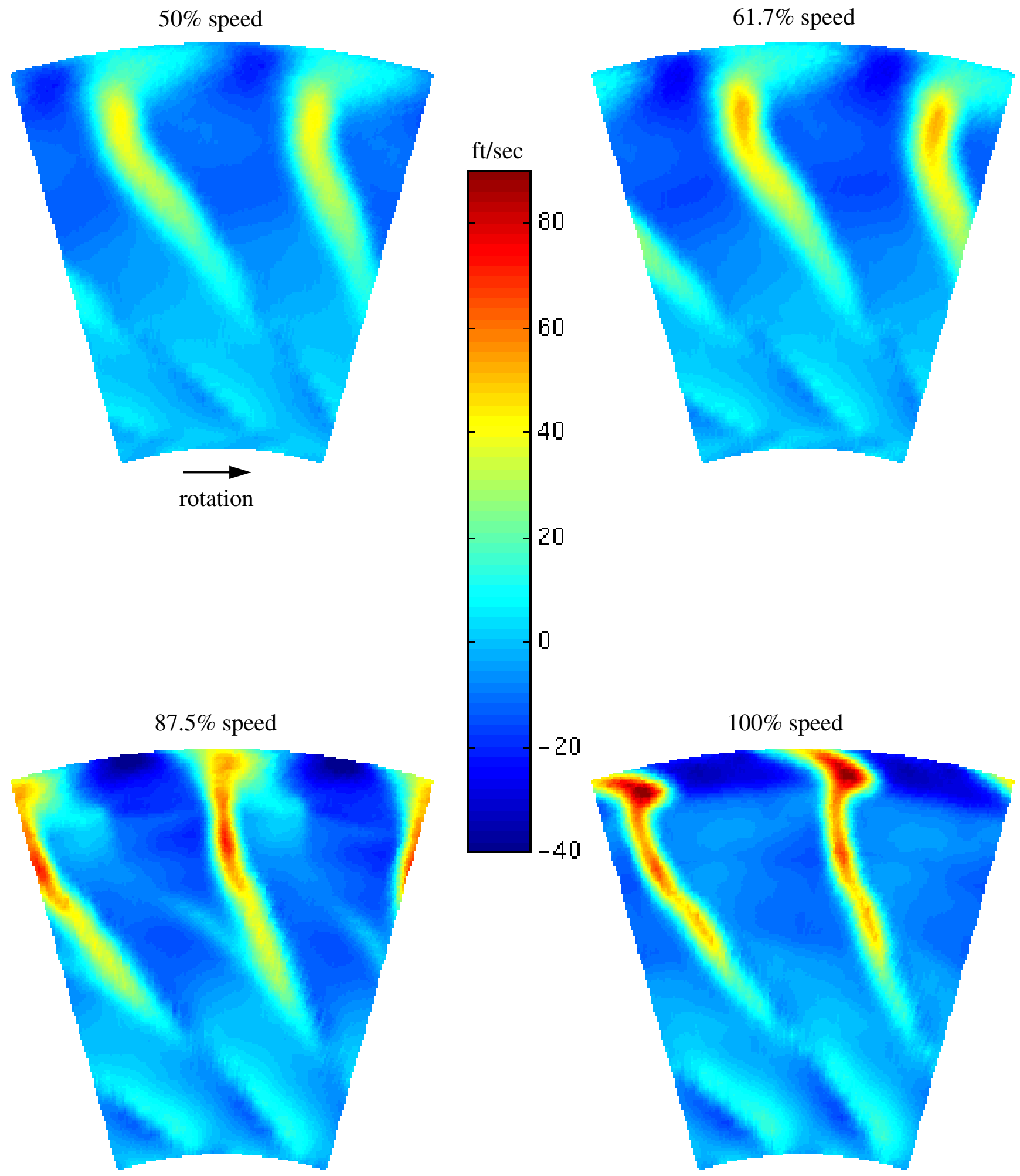

Figure 12. Difference between average passage tangential mean velocities and circumferentially-averaged tangential velocities measured at axial station LDV1 at four rotor speeds. 


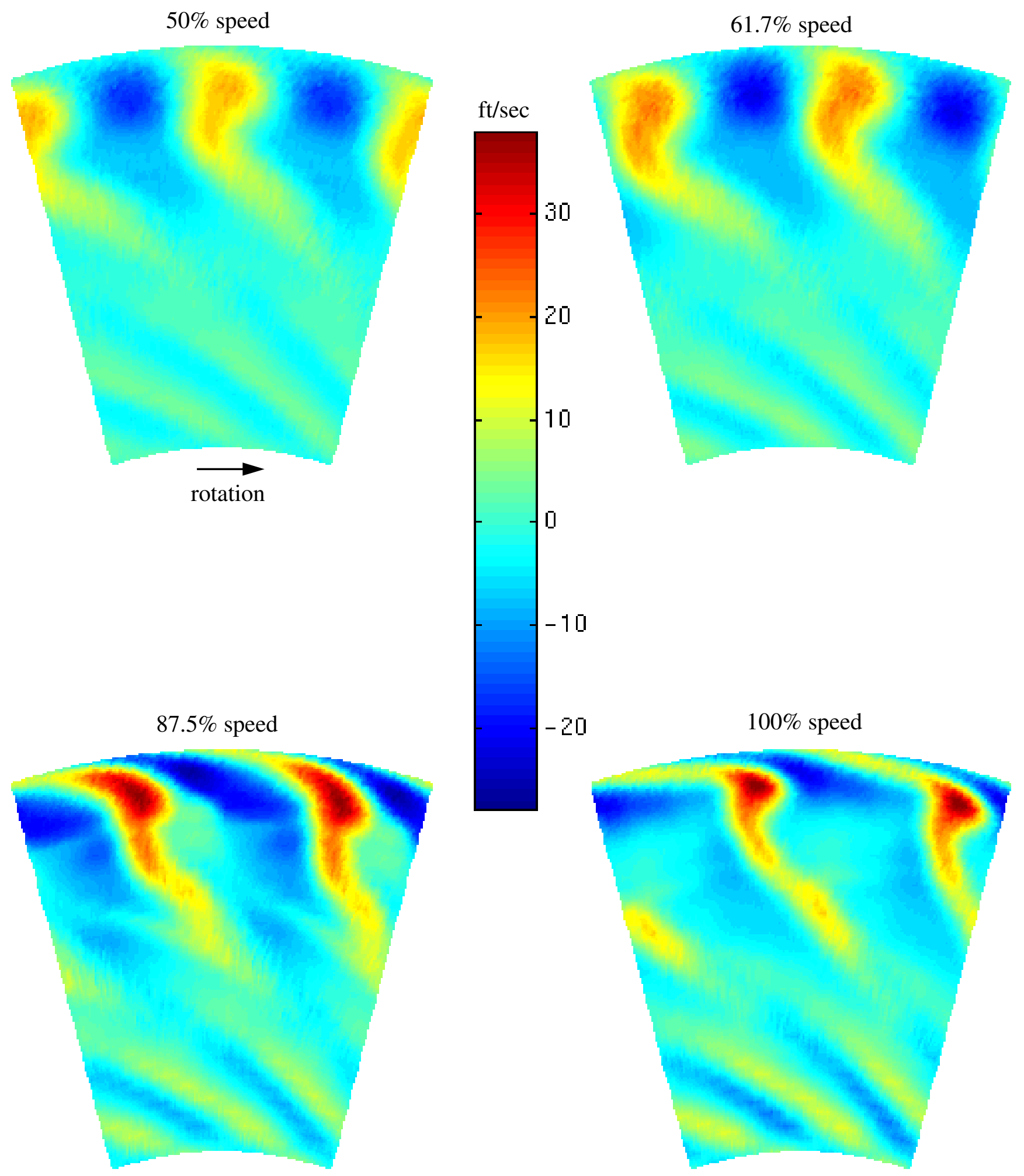

Figure 13. Difference between average passage tangential mean velocities and circumferentially-averaged tangential velocities measured at axial station LDV2 at four rotor speeds. 
A) Difference between maximum and minimum tangential mean velocities measured at axial station LDV1

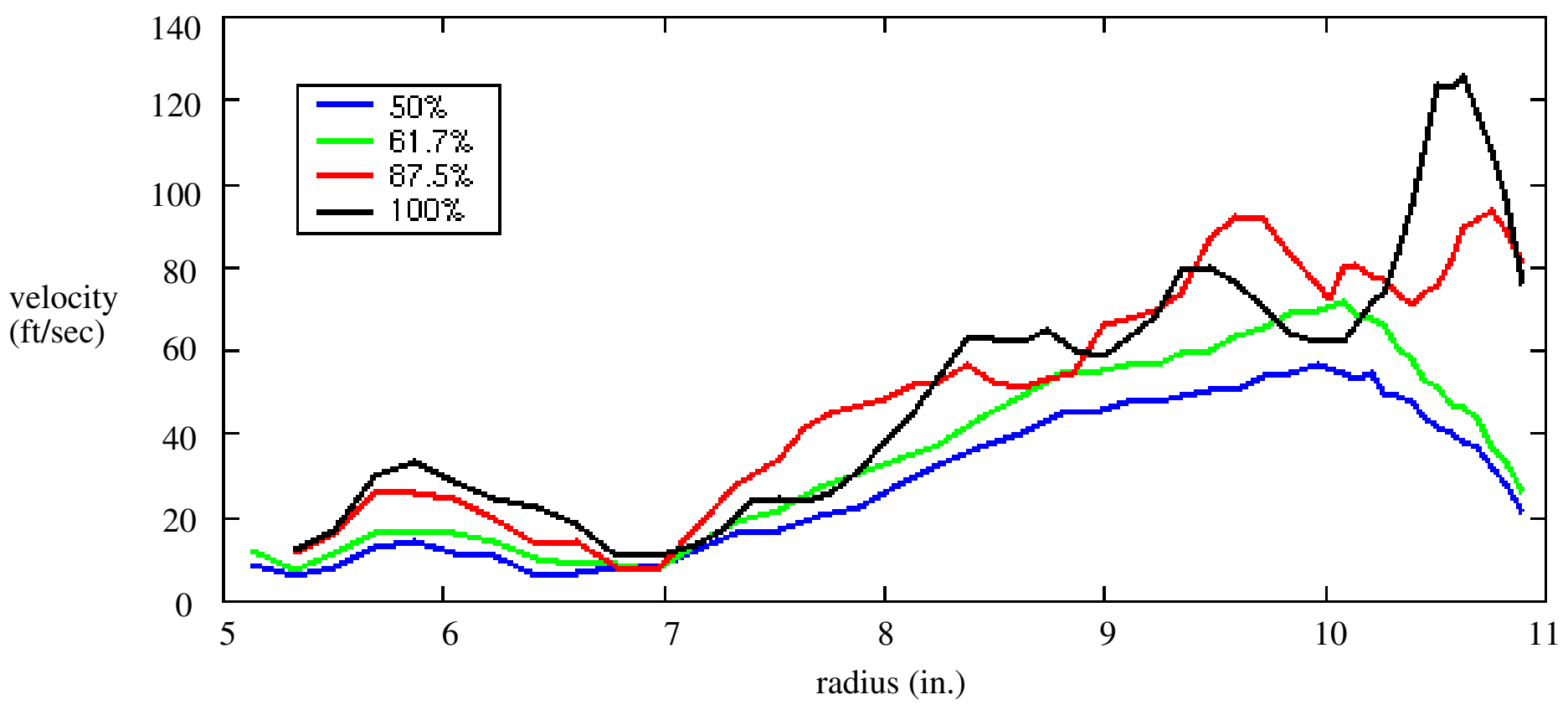

B) Difference between maximum and minimum tangential mean velocities measured at axial station LDV2

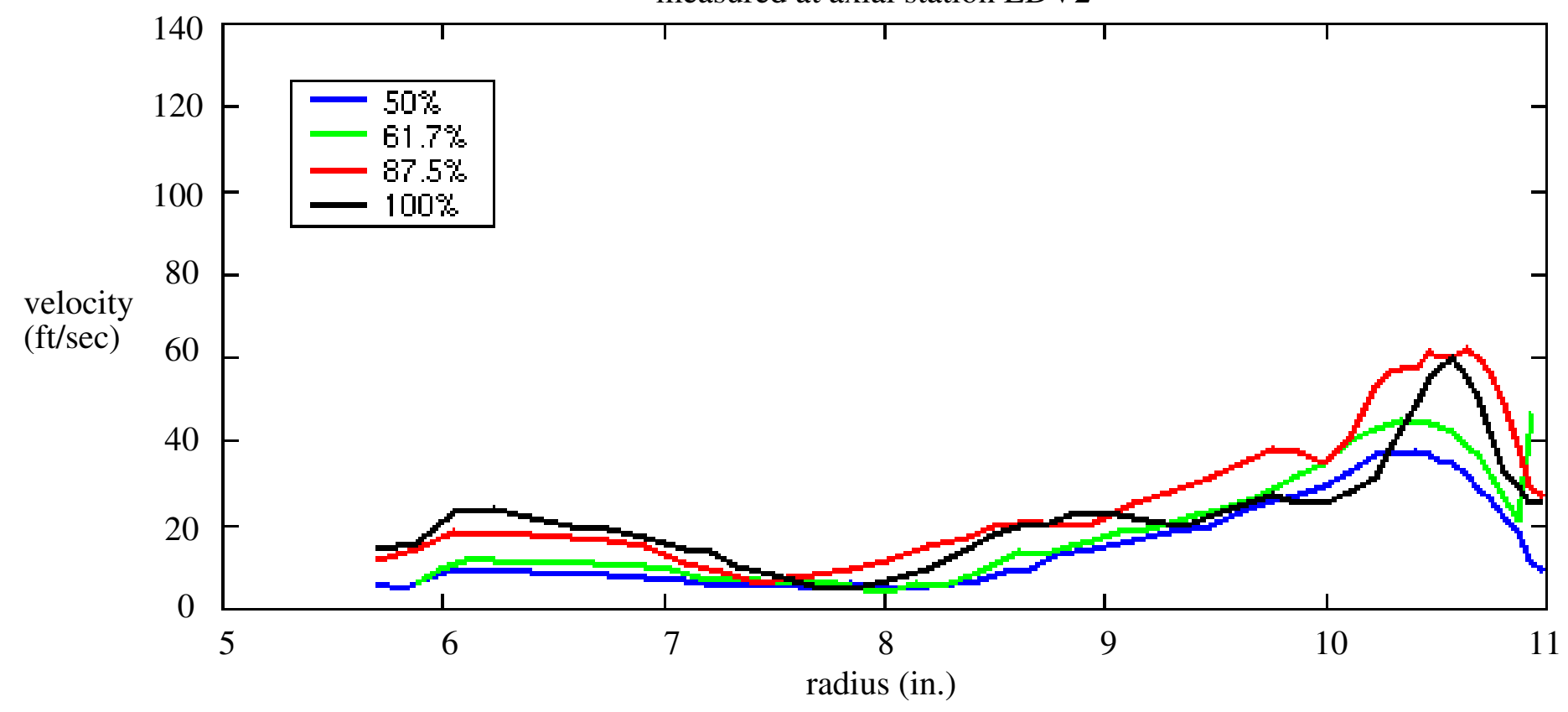

Figure 14. Amplitude of the tangential mean velocity oscillations measured in the wake of the R4 rotor at the four tested rotor speeds. 


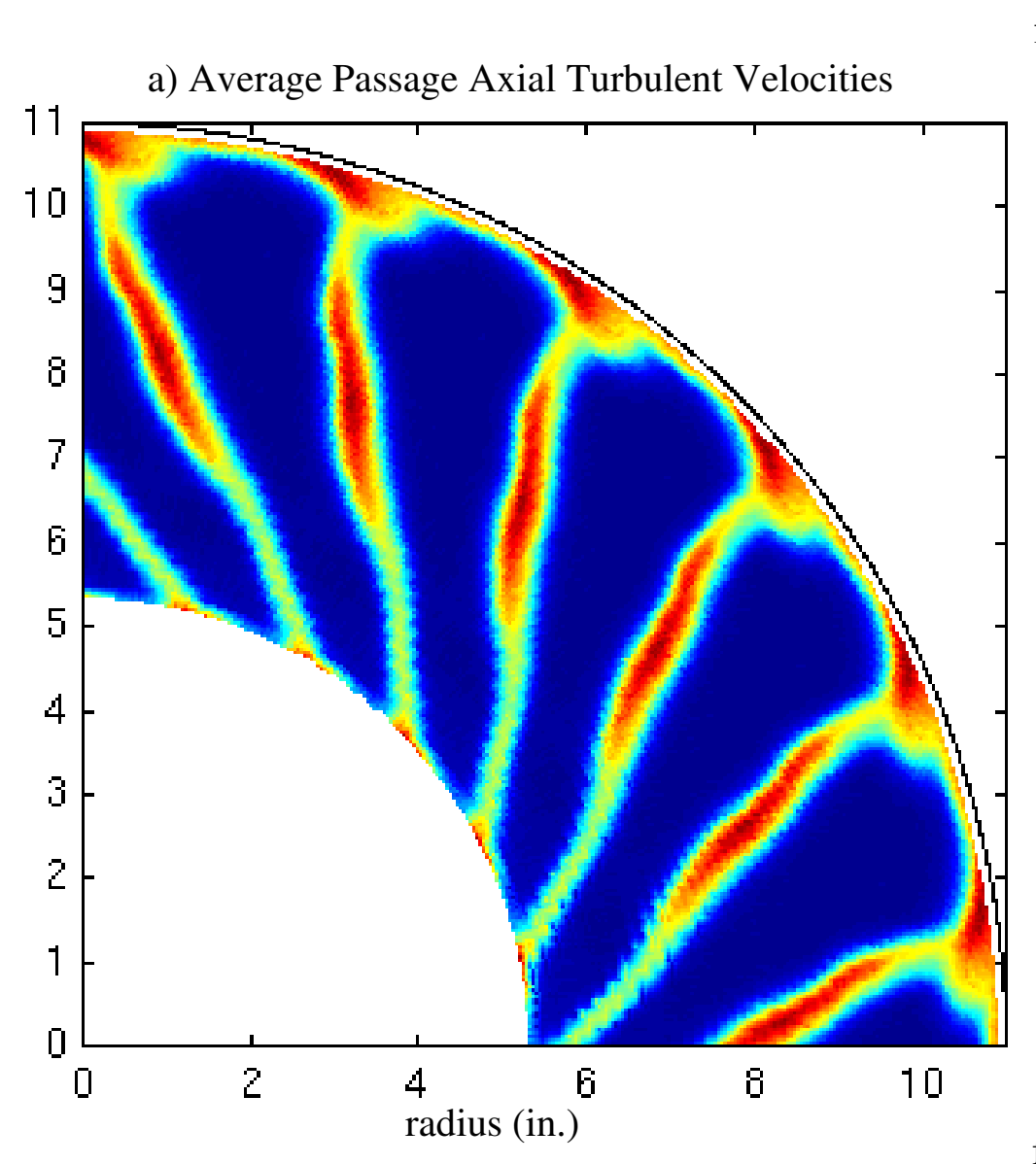

$\mathrm{ft} / \mathrm{sec}$

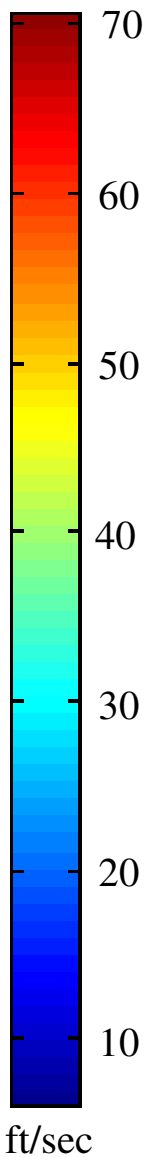

b) Average Passage Tangential Turbulent Velocities

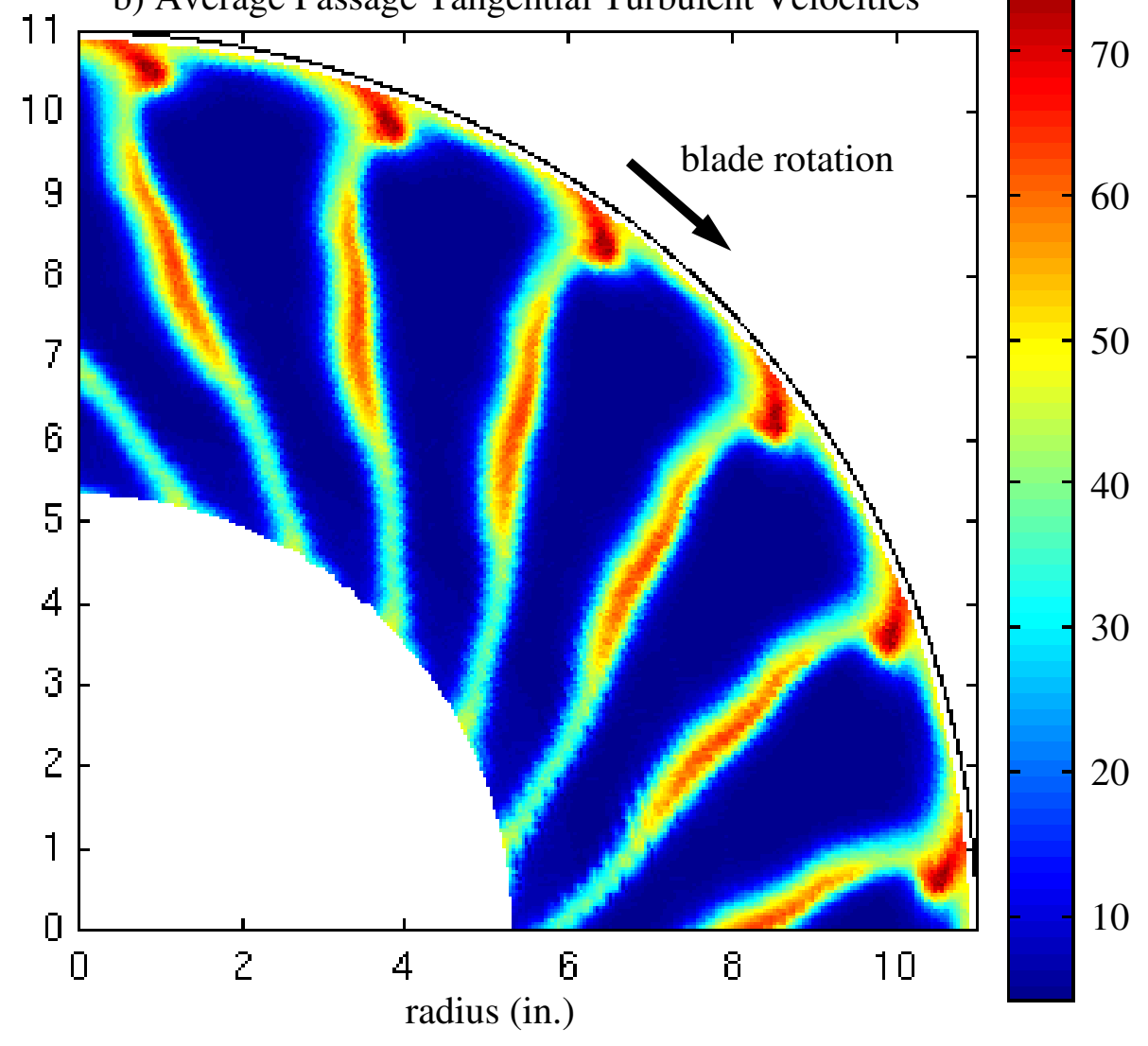

Figure 15. Average passage turbulent velocities measured at axial station LDV1 at 100\% rotor speed. 
$50 \%$ speed

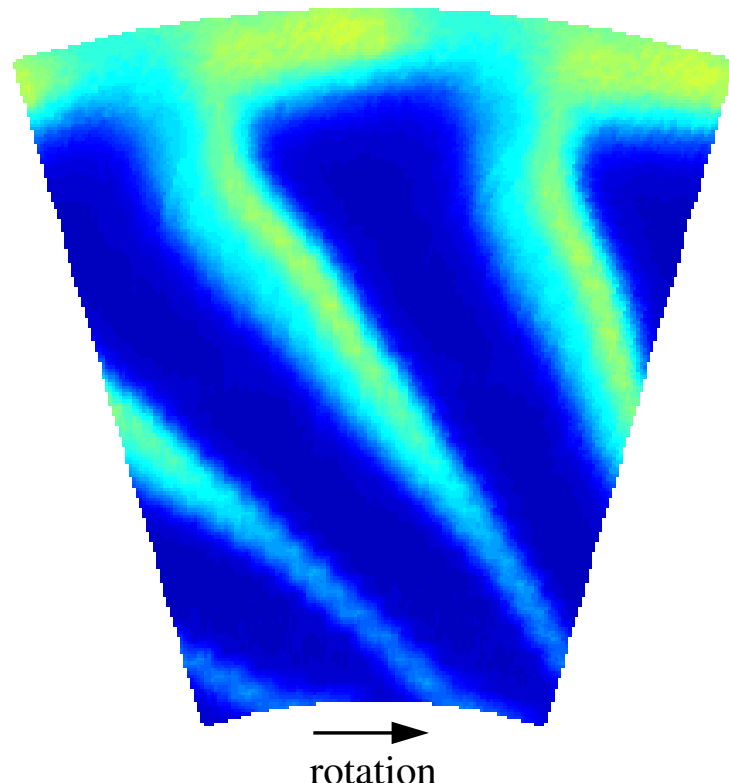

$87.5 \%$ speed

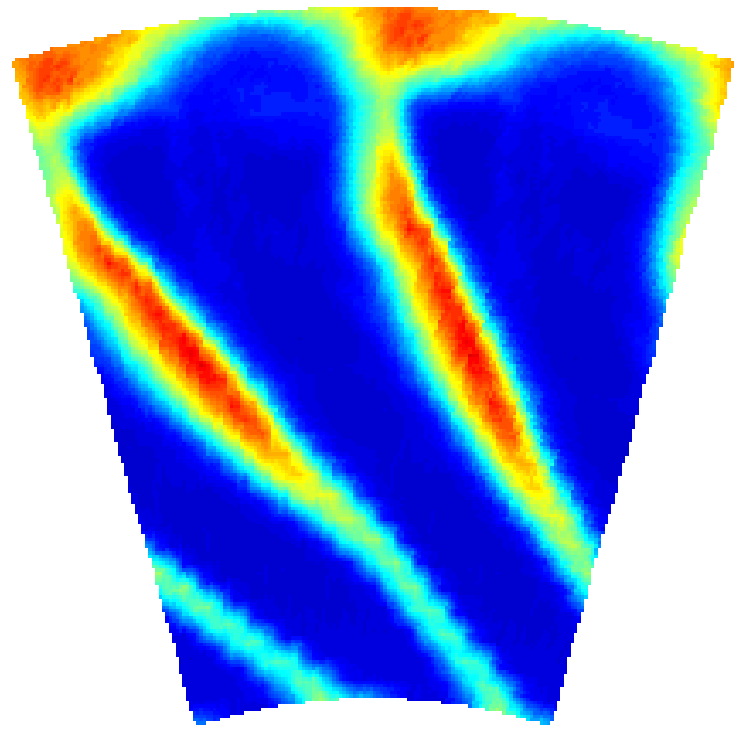

$61.7 \%$ speed

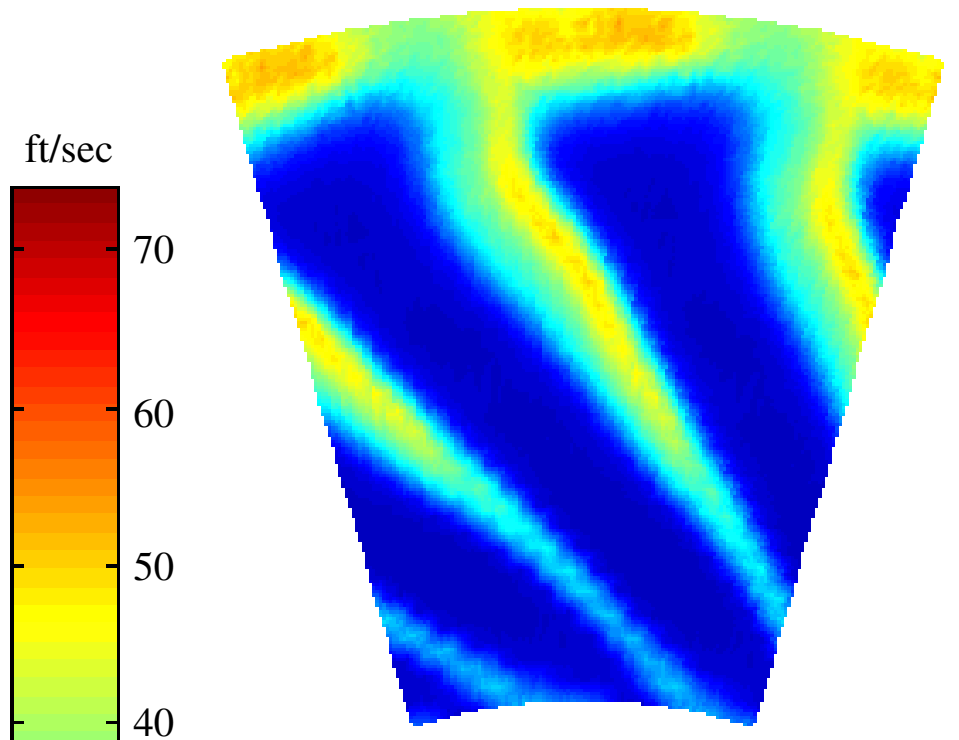

30

20

10

$100 \%$ speed

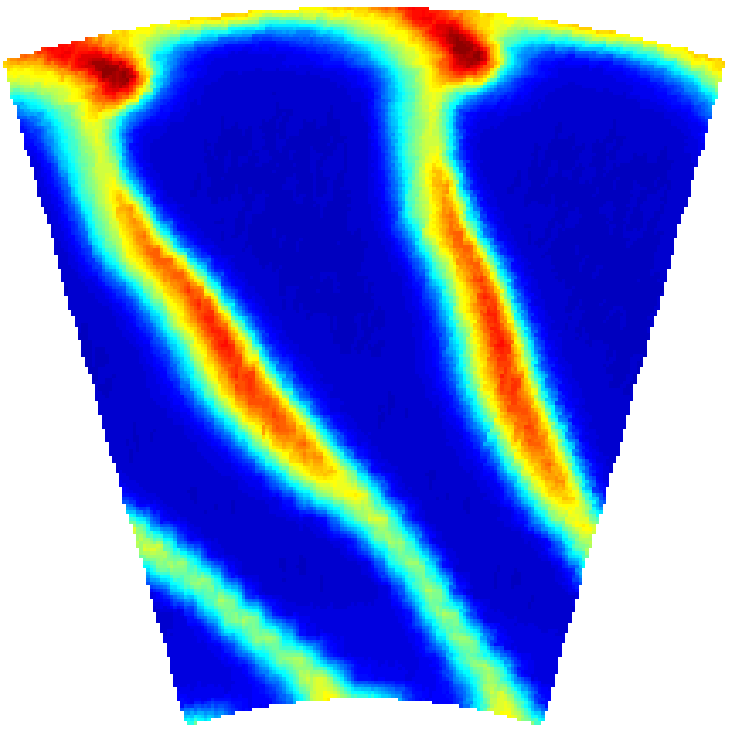

Figure 16. Average passage tangential turbulent velocities measured at axial station LDV1 at four rotor speeds. 
$50 \%$ speed

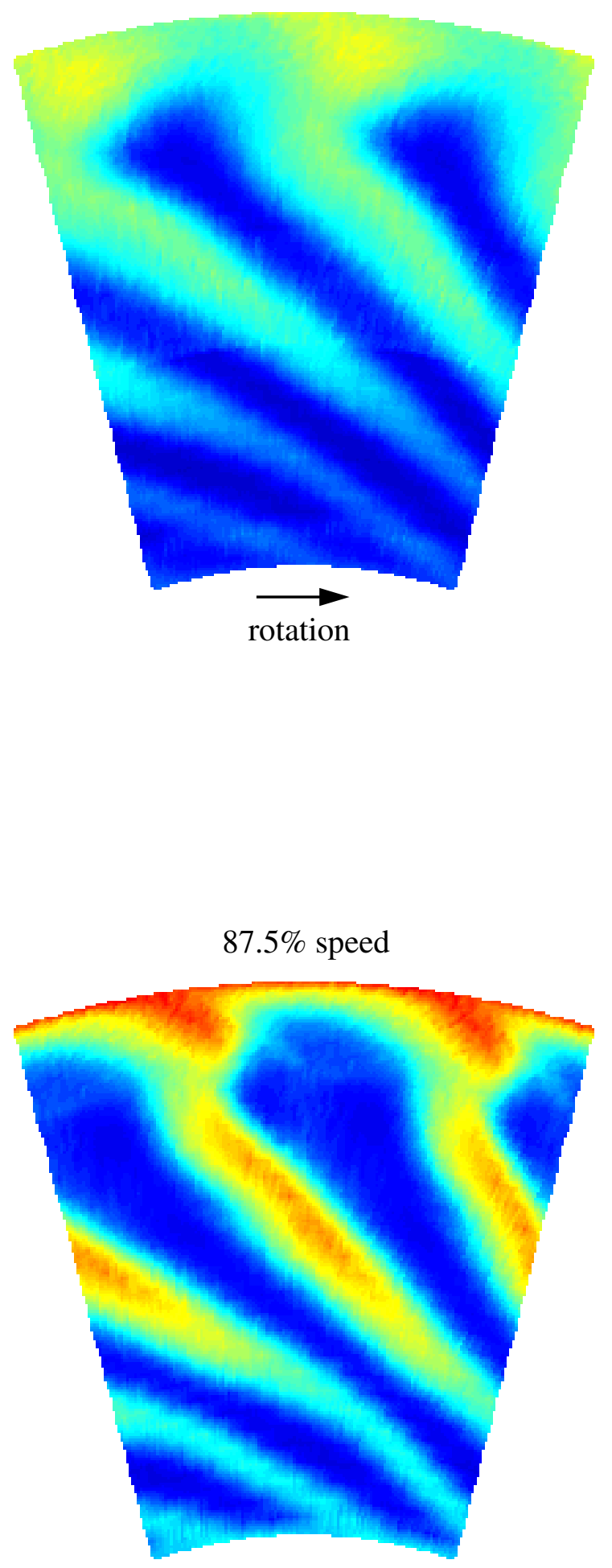

$61.7 \%$ speed

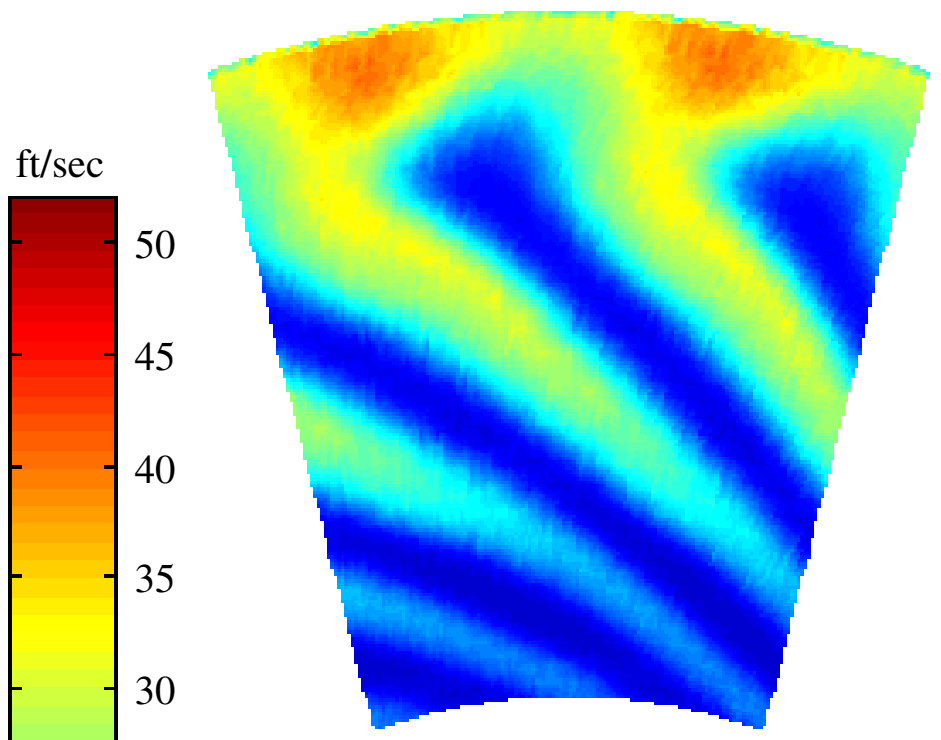

25

20

15

10

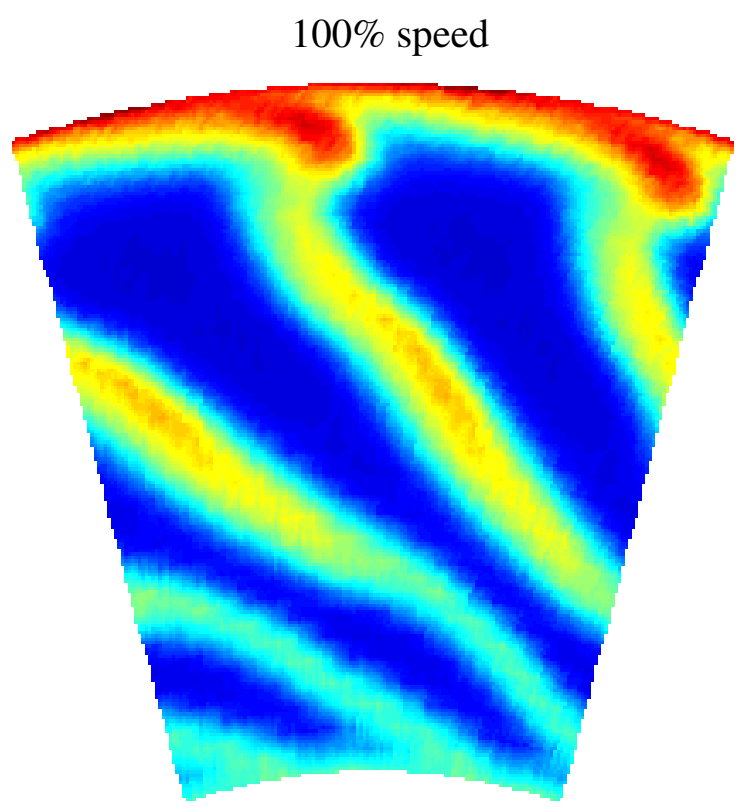

Figure 17. Average passage turbulent velocities measured at axial station LDV2 at four rotor speeds. 


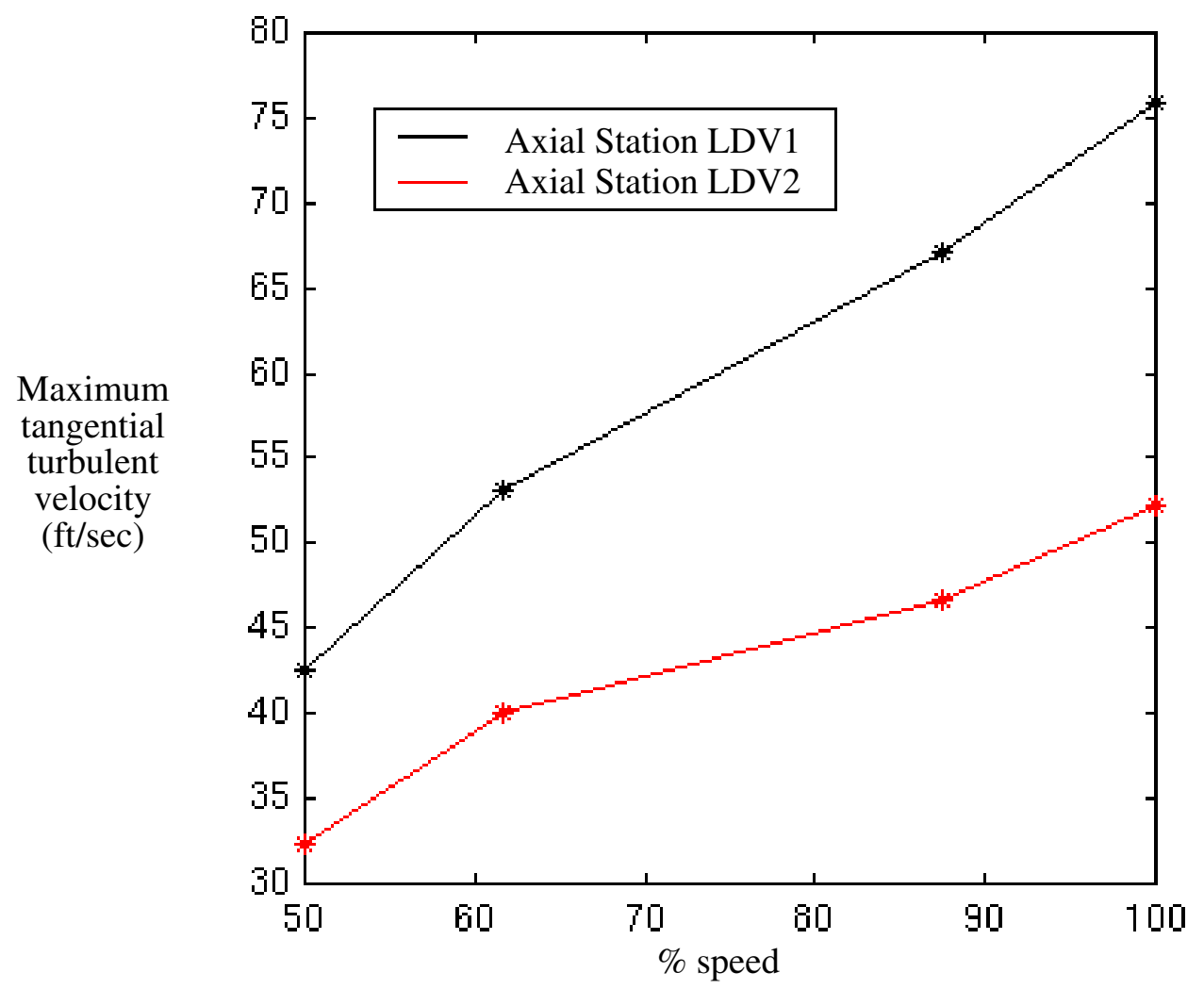

Figure 18. Variation of maximum measured tangential turbulent velocity with axial location and rotor speed.
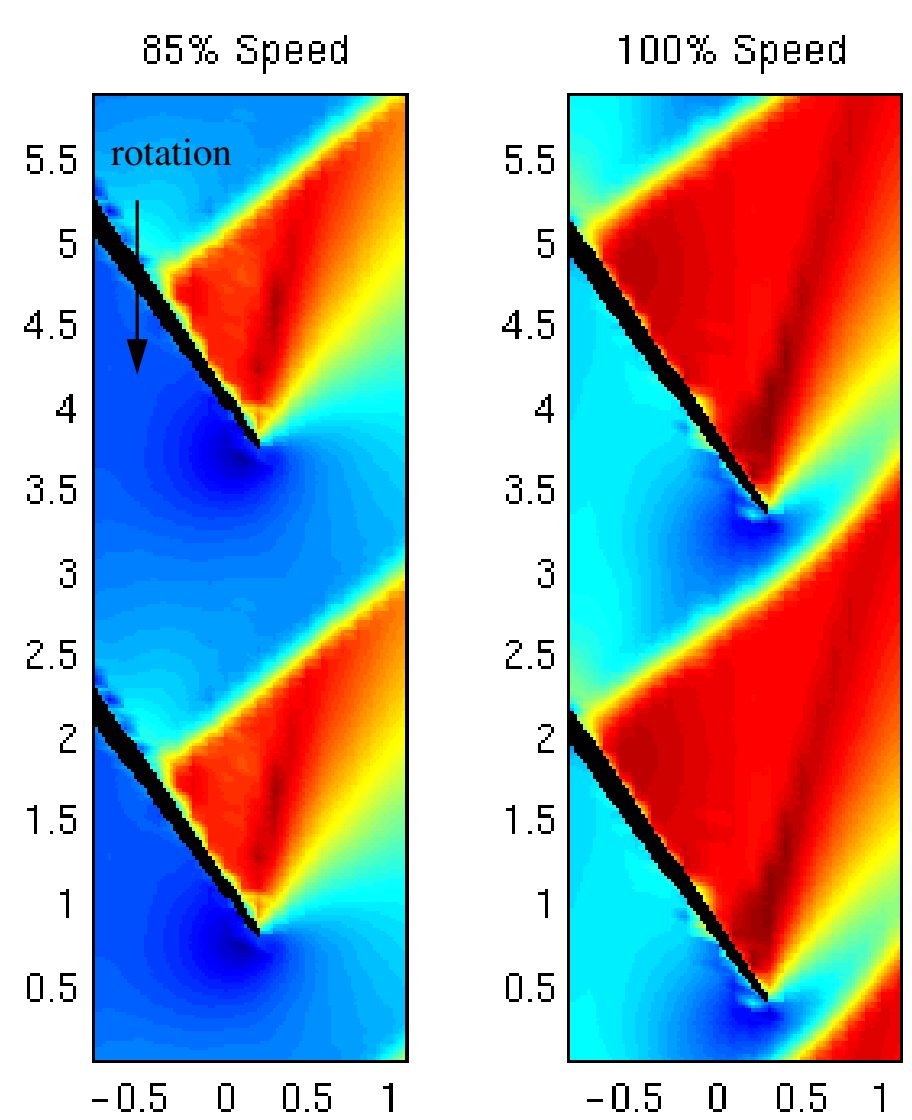

Rel Mach
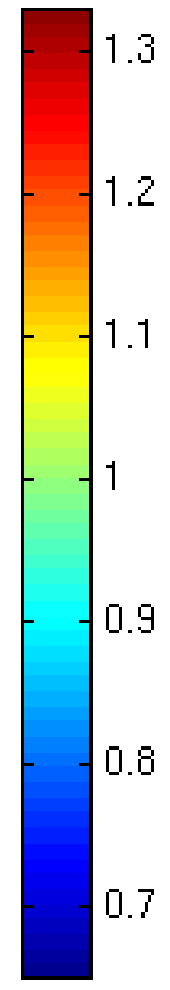

Figure 19. Average passage relative Mach number contours computed from measurements made during constant-radius shock location surveys at $\mathrm{r}=10.36 "(26.31 \mathrm{~cm})$. 

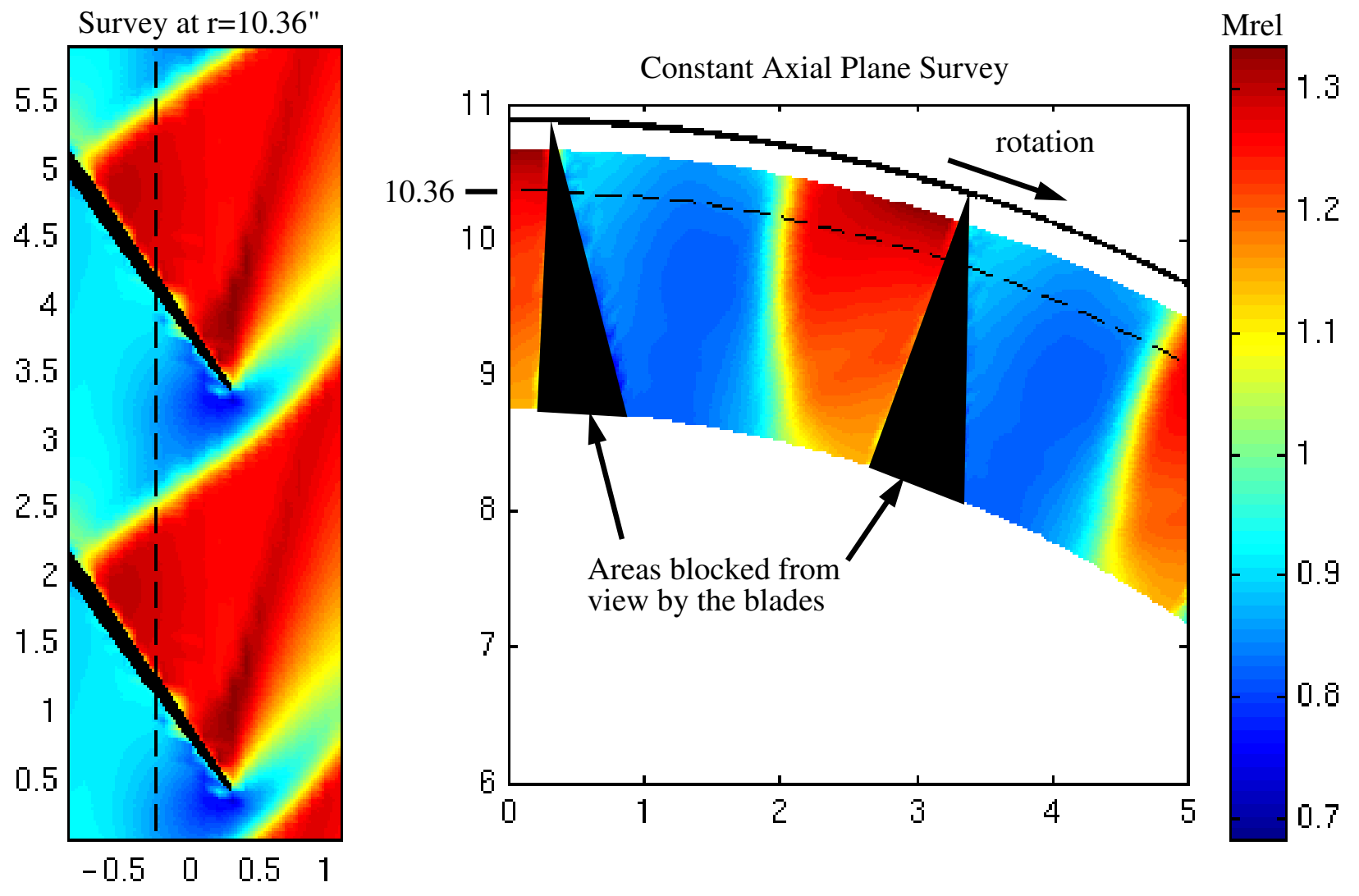

Figure 20. Average passage relative Mach number contours computed from measurements made with the rotor operating at $100 \%$ speed. Left plot is data acquired from constant-radius survey at $r=10.36 "$. Right plot is data acquired from constant-axial survey made at approximately $25 \%$ chord.
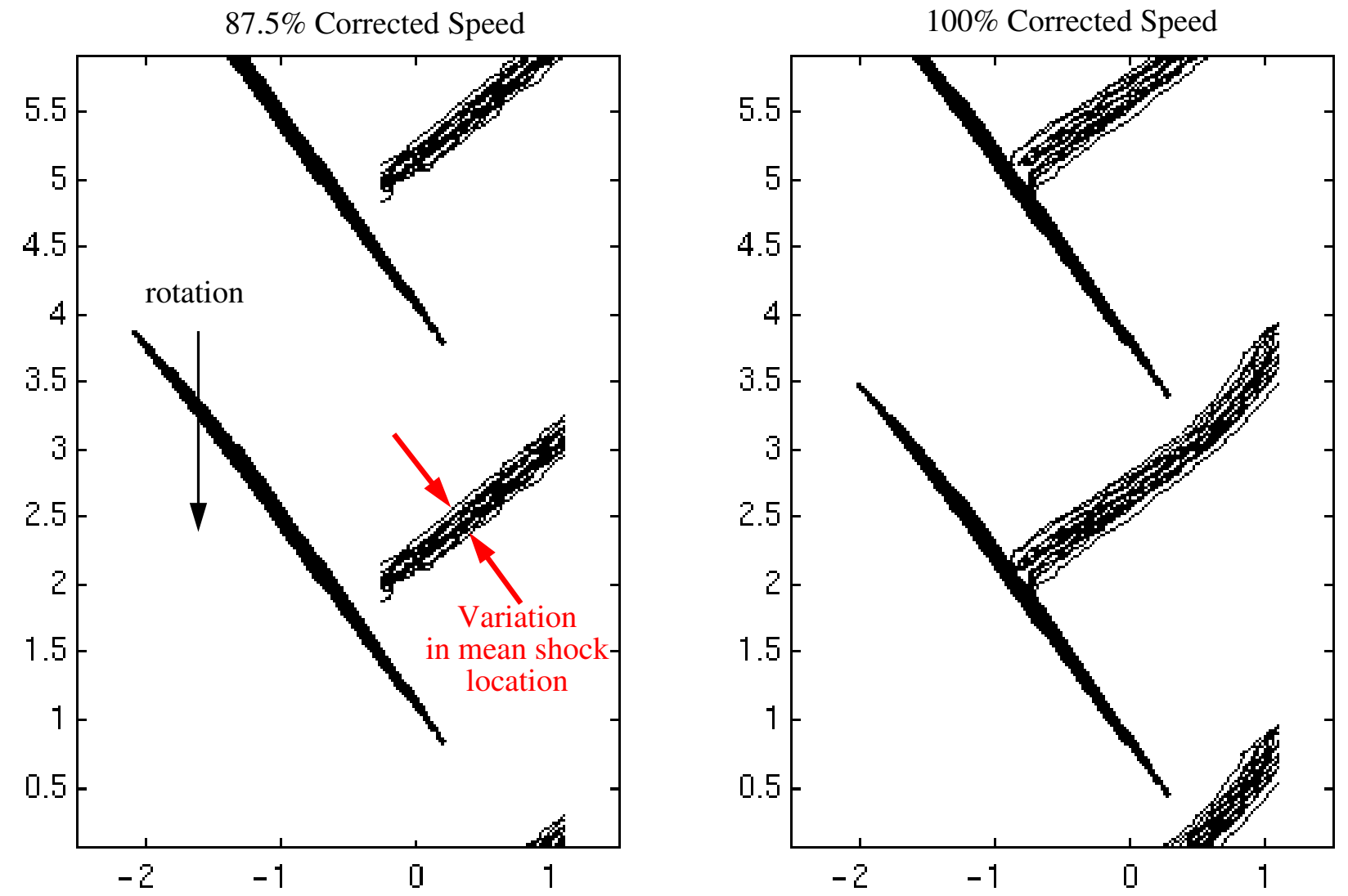

Figure 21. Overlay of Mach $=1.0$ contours measured in the 22 blade passages at 87.5 (left plot) and $100 \%$ (right plot) corrected speed. 


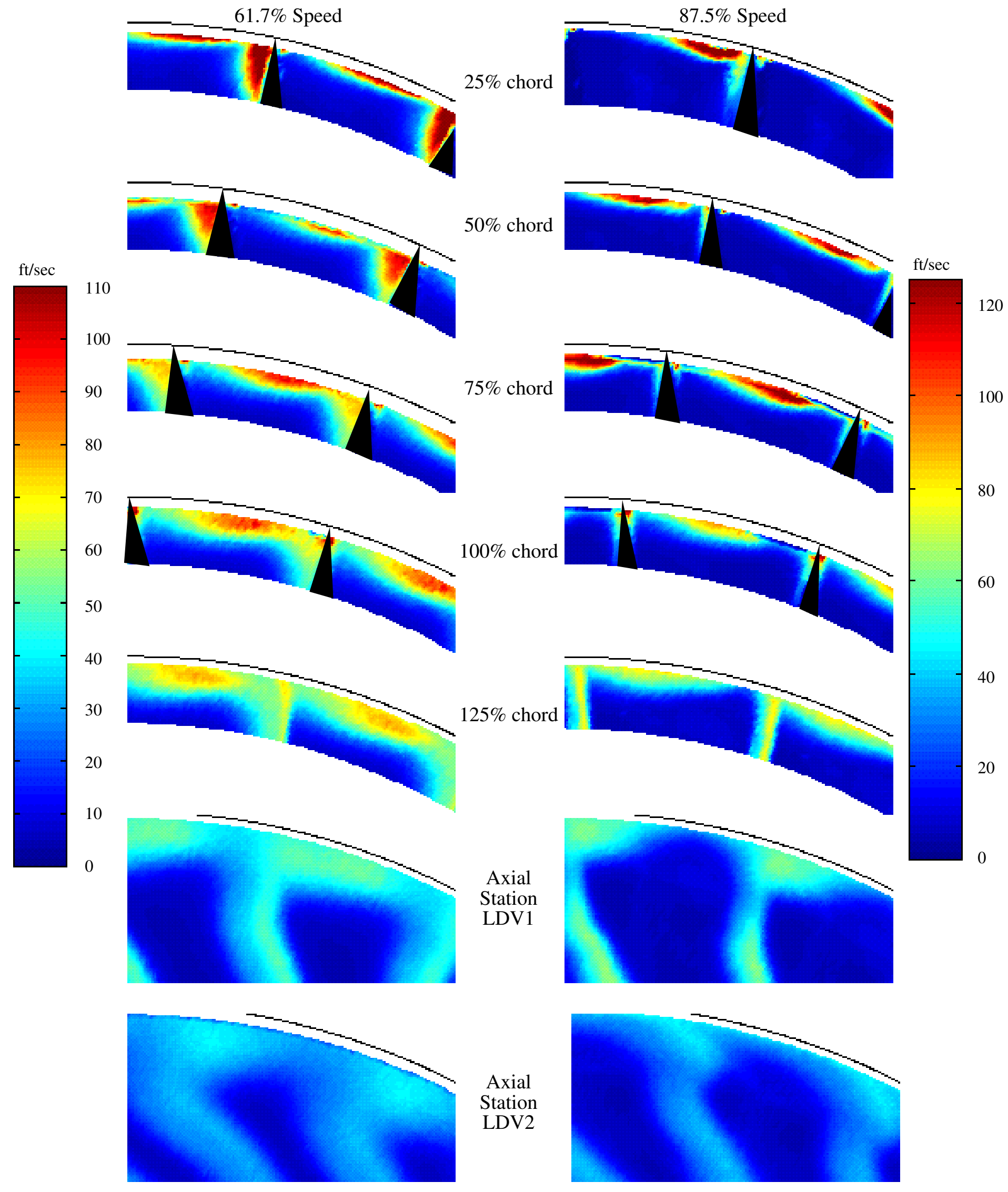

Figure 22. Contours of tangential turbulent velocity measured during constant axial plane surveys showing the tip flow within the blade passage and downstream of the rotor with the rotor at two speeds, $61.7 \%$ (left) and $87.5 \%$ (right). 


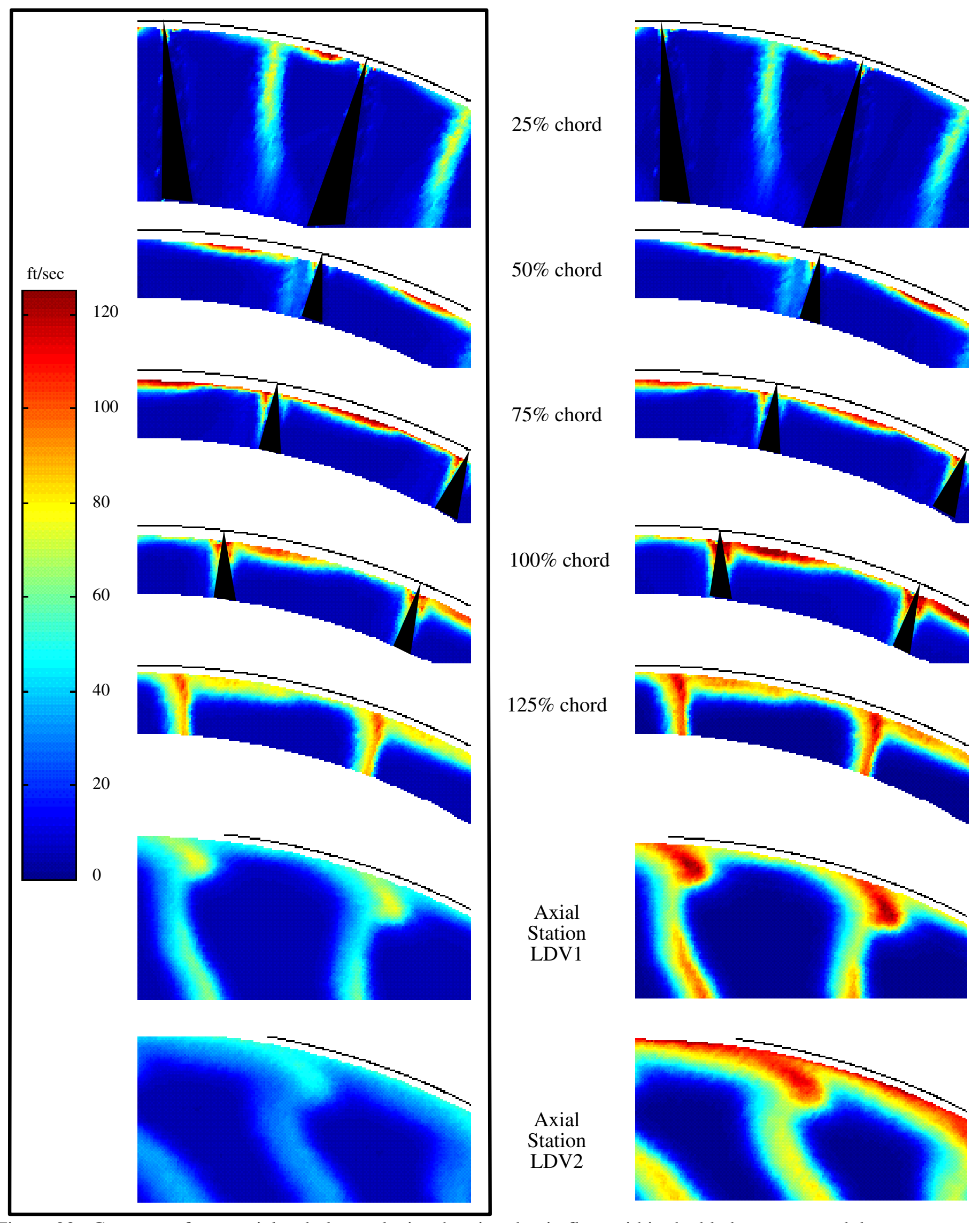

Figure 23. Contours of tangential turbulent velocity showing the tip flow within the blade passage and downstream of the rotor at $100 \%$ speed. The plots enclosed within the rectangle (the left column) all use the colorbar at the left. Each plot in the right column used a different colorbar (not shown) corresponding to the minimum and maximum values plotted within each set of the seven sets of data. 

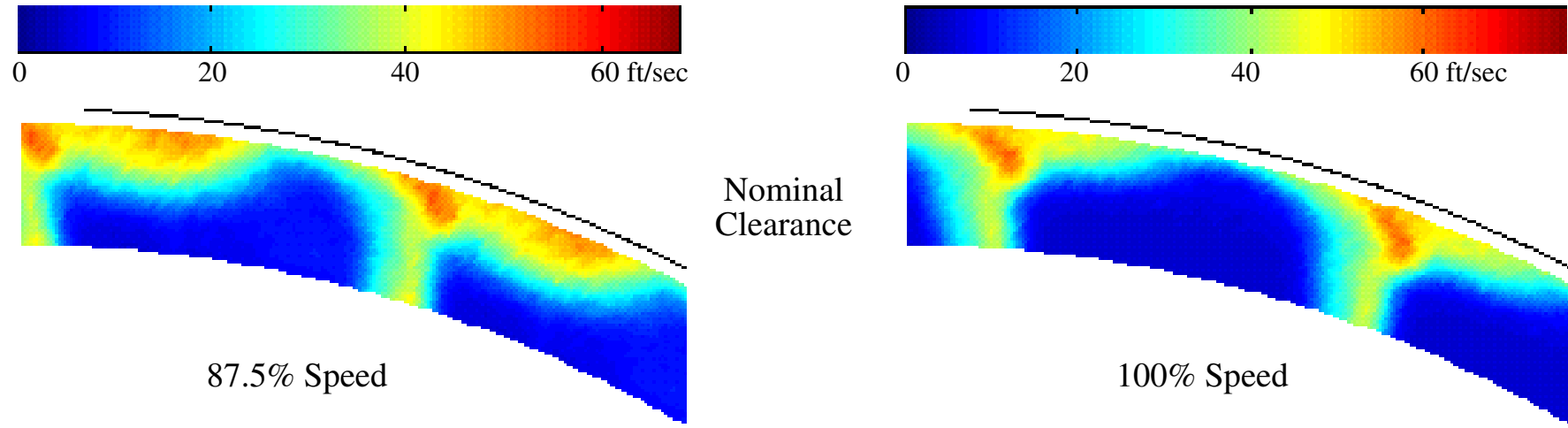

Nominal

Clearance
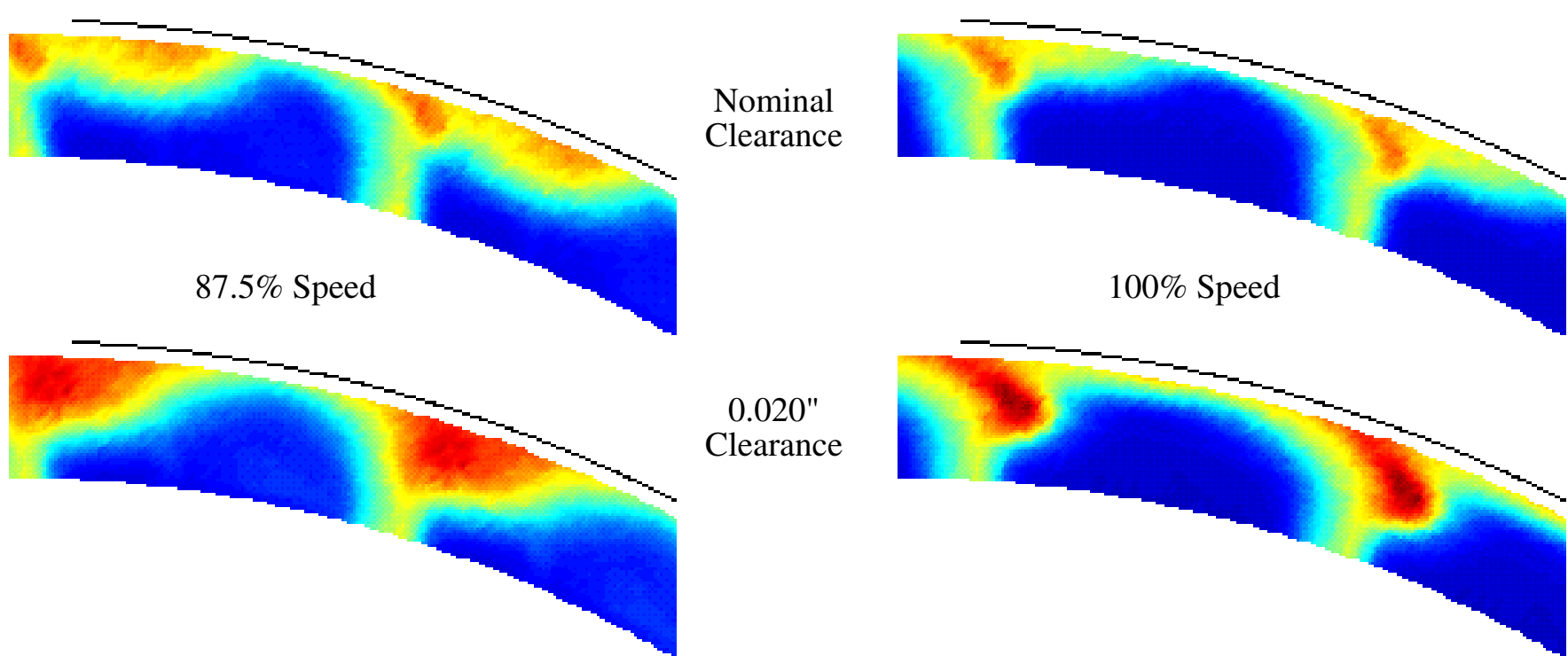

$0.020 "$

Clearance

Figure 24. Contours of average passage tangential turbulent velocity showing the tip flow measured at axial station LDV1 at two blade tip clearances and two rotor speeds.

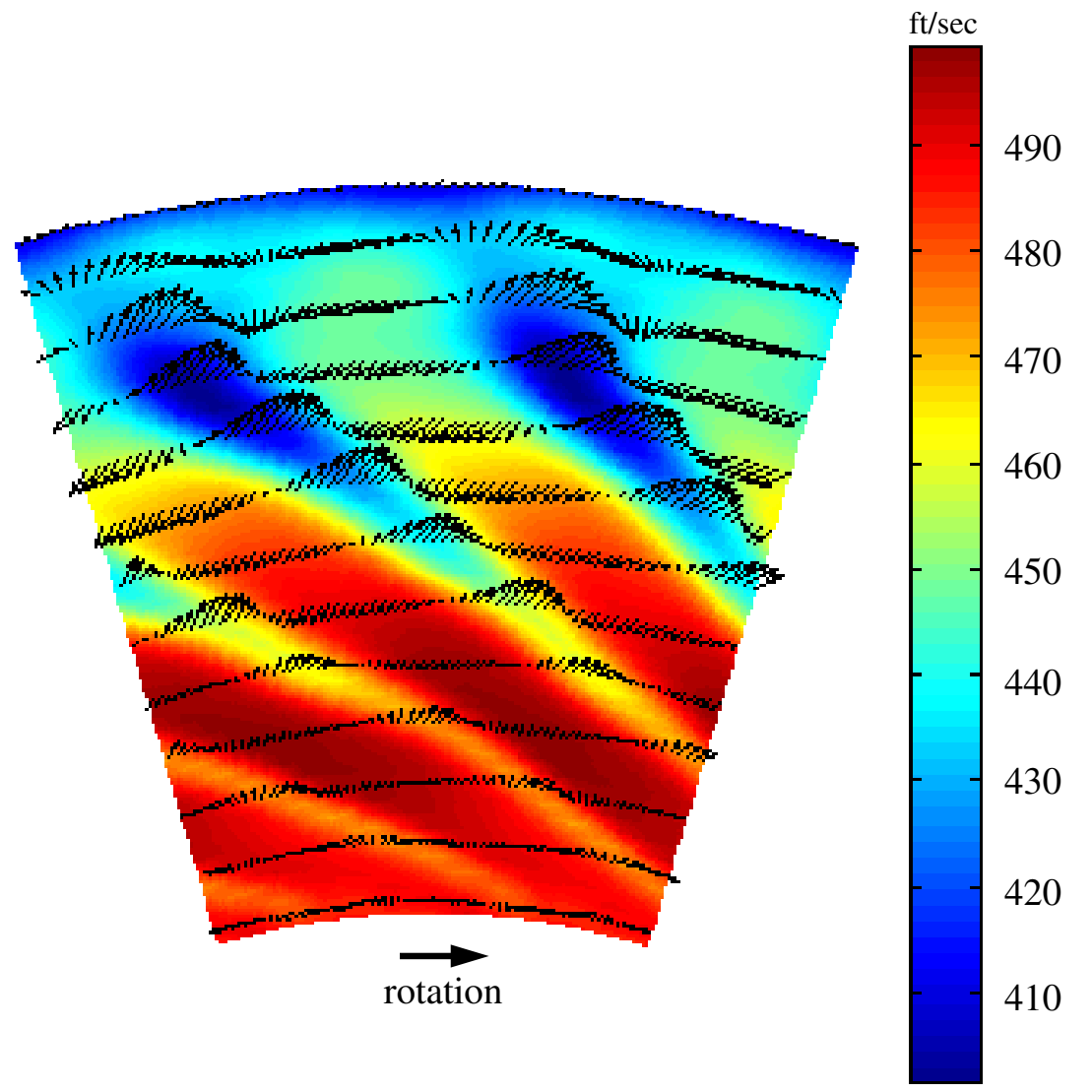

Figure 25. Hot-wire measurements of the rotor wake flow at station HW2 with the rotor at $61.7 \%$ speed. Color contours show streamwise velocity component; secondary velocity vectors are resultants computed from upwash and spanwise components. For reference, the longest plotted cross-stream velocity vector has a magnitude of $49 \mathrm{ft} / \mathrm{sec}$. 

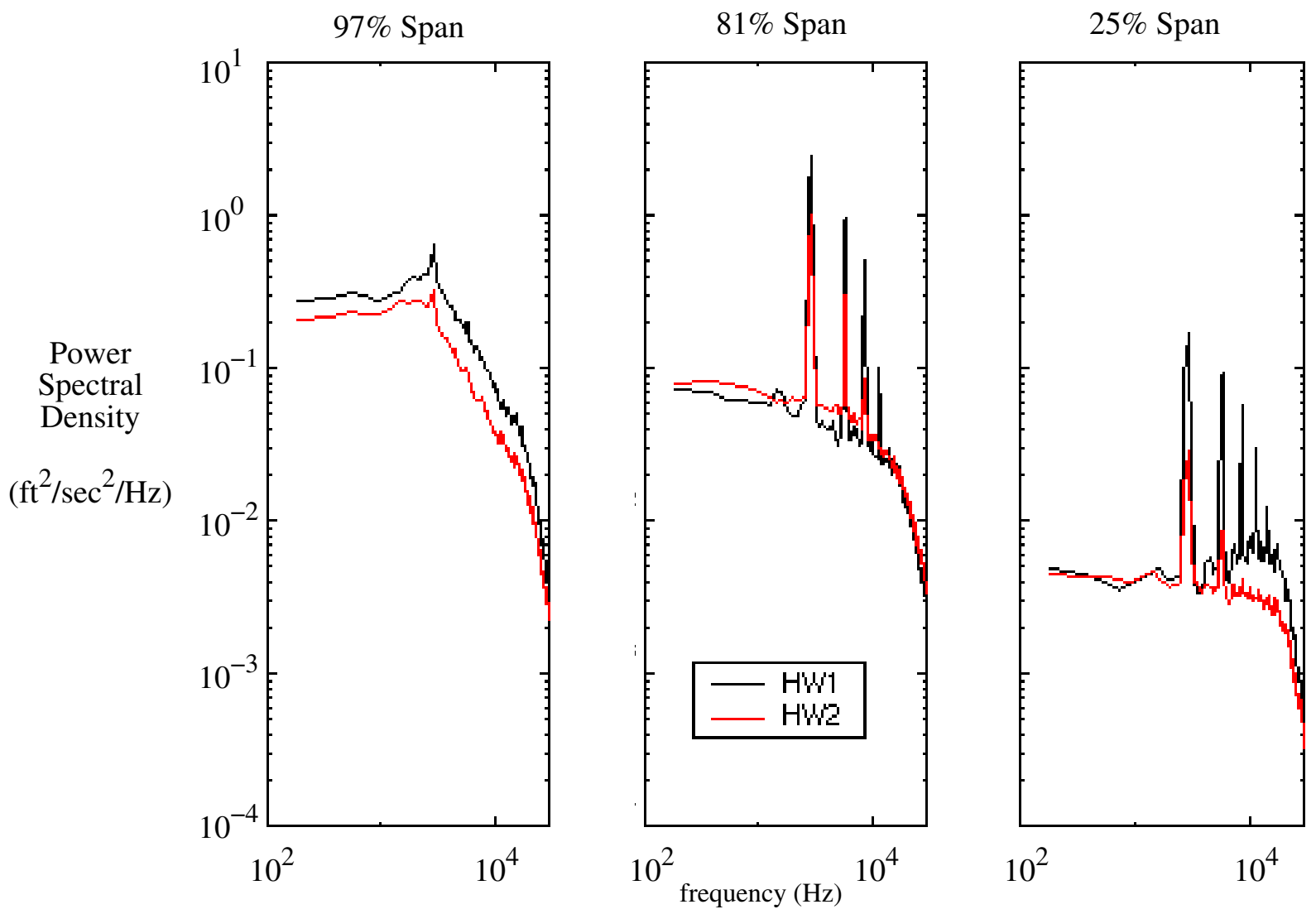

Figure 26. PSDs computed from upwash velocities measured in the rotor wake with the rotor operating at $61.7 \%$ speed (7808 RPMC).

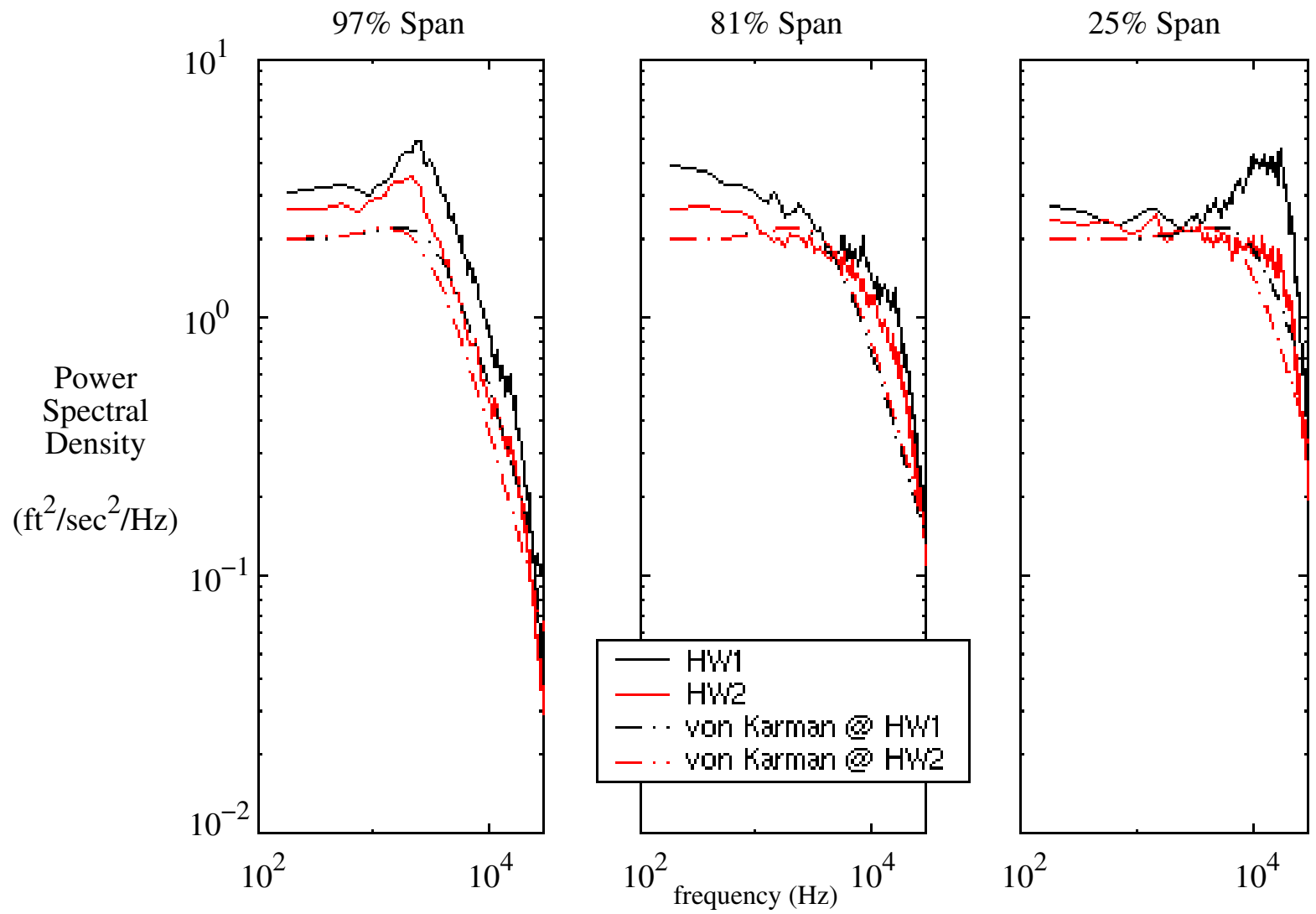

Figure 27. Comparison of experimental and von Karman model PSDs. Experimental PSDs were computed from same time traces used in Fig 26., but after removing periodic component of the signal. 


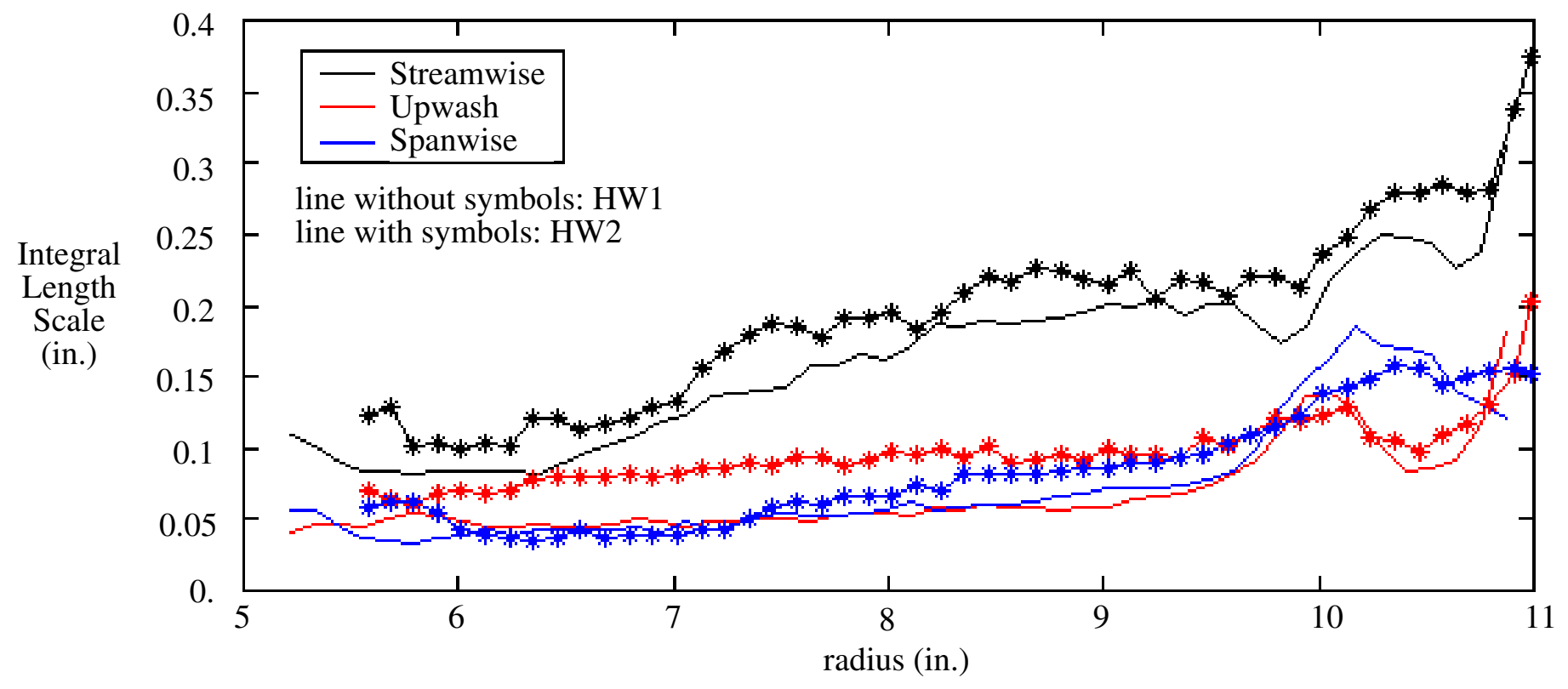

Figure 28. Radial distributions of turbulence integral length scale computed from velocity components measured in the rotor wake at $61.7 \%$ speed. 
Public reporting burden for this collection of information is estimated to average 1 hour per response, including the time for reviewing instructions, searching existing data sources, gathering and maintaining the data needed, and completing and reviewing the collection of information. Send comments regarding this burden estimate or any other aspect of this collection of information, including suggestions for reducing this burden, to Washington Headquarters Services, Directorate for Information Operations and Reports, 1215 Jefferson Davis Highway, Suite 1204, Arlington, VA 22202-4302, and to the Office of Management and Budget, Paperwork Reduction Project (0704-0188), Washington, DC 20503.

\begin{tabular}{|l|l|l}
\hline 1. AGENCY USE ONLY (Leave blank) & $\begin{array}{c}\text { 2. REPORT DATE } \\
\text { July } 2003\end{array}$ & $\begin{array}{r}\text { 3. REPORT TYPE AND DATES COVERED } \\
\text { Technical Memorandum }\end{array}$ \\
\hline
\end{tabular}

4. TITLE AND SUBTITLE 5. FUNDING NUMBERS

Steady and Unsteady Flow Field Measurements Within a NASA 22-Inch Fan Model

\section{AUTHOR(S)}

WBS-22-781-30-08

Gary G. Podboy, Martin J. Krupar, Stephen M. Helland, and Christopher E. Hughes

\section{PERFORMING ORGANIZATION NAME(S) AND ADDRESS(ES)}

National Aeronautics and Space Administration

John H. Glenn Research Center at Lewis Field

Cleveland, Ohio 44135-3191

8. PERFORMING ORGANIZATION REPORT NUMBER

\section{E-13924}

\section{SPONSORING/MONITORING AGENCY NAME(S) AND ADDRESS(ES)}

National Aeronautics and Space Administration

Washington, DC 20546-0001

10. SPONSORING/MONITORING AGENCY REPORT NUMBER

NASA TM-2003-212329

AIAA-2002-1033

\section{SUPPLEMENTARY NOTES}

Prepared for the 40th Aerospace Sciences Meeting and Exhibit sponsored by the American Institute of Aeronautics and Astronautics, Reno, Nevada, January 14-17, 2002. Responsible person, Gary G. Podboy, organization code 5940, 216-433-3916.

12a. DISTRIBUTION/AVAILABILITY STATEMENT 12b. DISTRIBUTION CODE

Unclassified - Unlimited

Subject Category: 01

Distribution: Nonstandard

Available electronically at http://gltrs.grc.nasa.gov

This publication is available from the NASA Center for AeroSpace Information, 301-621-0390.

\section{ABSTRACT (Maximum 200 words)}

Results are presented of an experiment conducted to investigate possible sources of fan noise in the flow developed by a 22-in. $(55.9 \mathrm{~cm})$ diameter turbofan model. Flow diagnostic data were acquired to identify possible sources of both tone and broadband noise. Laser Doppler velocimetry was used to characterize the tip flows that develop within the rotor blade passages, the wake flow downstream of the rotor, and the shock waves that develop on the blades when operated at transonic relative tip speeds. Single-point hot-wire measurements were made in the rotor wake to determine the frequency content and the length scales of the flow unsteadiness. The results document the changes in the rotor wake flow with both rotor speed and axial distance downstream of the rotor. The data also show the tip flow development within the blade passage, its migration downstream, and (at high rotor speeds) its merging with the blade wake of the following blade. Data also depict the variation of the tip flow with tip clearance. LDV data obtained within the blade passages at high rotor speeds illustrate the passage-to-passage variation of the mean shock position. Spectra computed from the single-point hot-wire measurements illustrate how the energy in the flow oscillations is split between periodic and random components, and how this split varies with both radial and axial position in the rotor wake.

\begin{tabular}{|c|c|c|c|}
\hline & \multirow{3}{*}{$\begin{array}{c}\text { 15. NUMBER OF PAGES } \\
36 \\
\text { 16. PRICE CODE }\end{array}$} \\
\hline \multirow{2}{*}{\multicolumn{3}{|c|}{$\begin{array}{l}\text { 14. SUBJECT TERMS } \\
\text { Aeroacoustics; Fan noise; Tone noise; Broadband noise; Rotor stator interaction noise; } \\
\text { Laser velocimetry; Hot-wire anemometry }\end{array}$}} & \\
\hline & & & \\
\hline $\begin{array}{l}\text { 17. SECURITY CLASSIFICATION } \\
\text { OF REPORT }\end{array}$ & $\begin{array}{l}\text { 18. SECURITY CLASSIFICATION } \\
\text { OF THIS PAGE }\end{array}$ & $\begin{array}{l}\text { 19. SECURITY CLASSIFICATION } \\
\text { OF ABSTRACT }\end{array}$ & 20. LIMITATION OF ABSTRACT \\
\hline Unclassified & Unclassified & Unclassified & \\
\hline
\end{tabular}

